\title{
Environmental Polymer Degradation: Using the Distonic Radical Ion Approach to Study the Gas-Phase Reactions of Model Polyester Radicals
}

\author{
Bethany I. Taggert, Richard A. J. O’Hair, ${ }^{\circledR}$ and Uta Wille*(ْ) \\ School of Chemistry, Bio21 Institute, The University of Melbourne, 30 Flemington Road, Parkville, Victoria 3010, Australia
}

Supporting Information

ABSTRACT: A novel precursor to the distonic O- and C-centered radical cations $\mathrm{Oxo}^{+} \mathrm{O}^{\bullet}$ and $\mathrm{Oxo}^{+} \mathrm{C}^{\bullet}$ was designed and synthesized, which represents model systems for radicals produced during polyester degradation. The precursor is equipped with a nitrate functional group, which serves as a masked site for these alkoxyl and carbon radicals that are unleashed through collision-induced dissociation (CID). $\mathrm{Oxo}^{+} \mathrm{O}^{\bullet}$ and $\mathrm{Oxo}^{+} \mathrm{C}^{\bullet}$ feature a cyclic carboxonium ion as permanent charge tag to enable monitoring their ion-molecule reactions on the millisecond to second time scale in the ion trap of the mass spectrometer. The reactions of $\mathrm{Oxo}^{+} \mathrm{O}^{\bullet}$ and $\mathrm{Oxo}^{+} \mathrm{C}^{\bullet}$ with cyclohexene, cyclohexadiene, ethyl acetate, 1,1dimethoxyethane, and 1,2-dimethoxyethane, which exhibit structural features present in both intact and defective polyesters, were explored through product and kinetic studies to identify "hot spots" for radical-induced damage in polyesters. All reactions with $\mathrm{Oxo}^{+} \mathrm{O}^{\bullet}$ were extremely fast and proceeded predominantly through HAT. Oxo ${ }^{+} \mathrm{C}^{\bullet}$ was about two orders of magnitude less reactive and did not noticeably damage aliphatic ester moieties through hydrogen abstraction on the time scale of our experiments. Radical addition to alkene $\pi$ systems was identified as an important pathway for $C$-radicals, which needs to be included in polymer degradation mechanisms.

\section{INTRODUCTION}

Synthetic polymers are among the most widely used materials due to their extremely diverse properties, which are controlled by their composition, the synthetic and processing techniques as well as their chain length, in conjunction with any secondary bonding interactions between polymer molecules. Environmental exposure of polymers leads to dramatic changes of their properties resulting in decreased service life and limited usage.

Environmental polymer degradation can occur hydrolytically, thermally, and by UV-light. ${ }^{1}$ Both thermal and photochemical degradation can proceed through radical pathways. Key intermediates are polymer-derived peroxyl radicals, $\mathrm{ROO}^{\bullet}$, resulting from reaction of a carbon-centered polymer radical, $\mathrm{R}^{\bullet}$ (which can be formed, for example, through mechanical stress), ${ }^{2}$ with oxygen, $\mathrm{O}_{2}$. $\mathrm{ROO}^{\bullet}$ are believed to act as carrier in a radical chain process that propagates damage through abstraction of a hydrogen atom from a neighboring polymer strand to form a hydroperoxide, $\mathrm{ROOH}$, and a new polymer radical $\mathrm{R}^{\bullet}$. Although this "autoxidation" mechanism was originally only proposed for the degradation of rubber, ${ }^{3-6}$ it has been generally adapted to rationalize radical degradation in any polymer, irrespective of their structure. However, a recent high-level computational study clearly showed that this radical propagation is energetically unfavorable in polymers without activated $\mathrm{C}-\mathrm{H}$ bonds, ${ }^{7}$ which suggests that important pathways in environmental polymer degradation remain unrecognized. In fact, early degradation products, which could shed light onto the mechanism(s), have been rarely identified. ${ }^{8-10}$

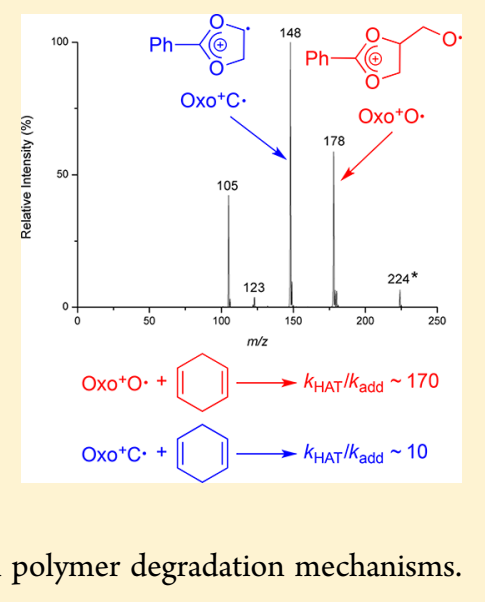

Since reactions between $\mathrm{O}_{2}$ and polymer radicals $\mathrm{R}^{\bullet}$ occur at the interface between gas-phase and polymer surface, gas-phase physical organic chemistry studies should provide valuable insights into reactive intermediates associated with the formation of early degradation products. A general way of investigating gas-phase radical reactions is by taking advantage of the multistage mass spectrometry capability of ion traps to generate distonic radical ions and then study their reactivity. ${ }^{11}$ The chemistry of any charged species in the reaction system can be directly monitored in a time-resolved fashion to obtain kinetic data for individual reaction steps. This approach has been used to investigate radical reactions of relevance to numerous fields, for example, organic synthesis, ${ }^{12,13}$ atmospheric chemistry, ${ }^{14-18}$ and biological chemistry. ${ }^{19,20}$ We have recently employed this methodology to study the reaction of distonic $N$-methylpyridinium peroxyl radical cations $\left(\mathrm{Pyr}^{+} \mathrm{OO}^{\bullet}\right),{ }^{12,13}$ which were used as a simplified model for $\mathrm{ROO}^{\circ}$, with various substrates that exhibit typical structural motifs in intact or defective polyesters. ${ }^{21}$ Scheme 1 outlines the reaction of $\mathrm{Pyr}^{+} \mathrm{OO}^{\bullet}$ with cyclohexene, which shows that allylic hydrogen atom transfer (HAT; pathway (a)) is only a minor pathway.

The major reaction channel involves addition of $\mathrm{Pyr}^{+} \mathrm{OO}^{\bullet}$ to the alkene $\pi$ system, followed by rapid homolytic $\mathrm{O}-\mathrm{O}$ bond fragmentation to yield an epoxide and $\mathrm{Pyr}^{+} \mathrm{O}^{\bullet}$ (pathway (b)),

Received: May 4, 2017

Revised: June 22, 2017

Published: June 23, 2017 
Scheme 1. Reaction of $\mathrm{Pyr}^{+} \mathrm{OO}^{\bullet}$ with Cyclohexene ${ }^{21}$

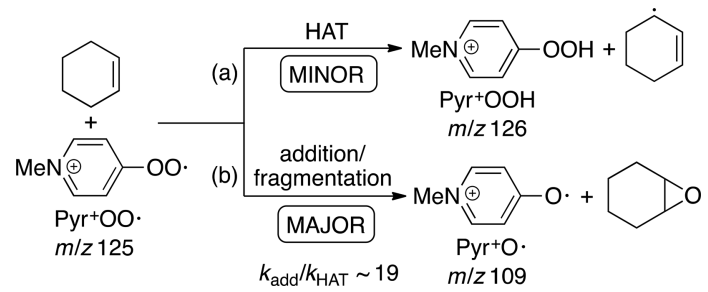

which is a reactive oxygen-centered radical species $\left(\mathrm{RO}^{\bullet}\right)$ that reacts rapidly through HAT and radical addition. ${ }^{21}$ Formation of highly reactive $\mathrm{RO}^{\bullet}$ through reaction of $\mathrm{ROO}^{\bullet}$ with $\pi$ systems in alkenes has not been considered as pathway in radical polymer degradation so far. This not only highlights the deficiencies of the current mechanistic rationale but also demonstrates the power of the distonic radical ion approach, which allows the discovery of new, previously unidentified degradation pathways.

In this work, we have designed and synthesized the novel distonic radical cation precursor (1) to perform a mass spectrometric study of the reaction kinetics and products of two aliphatic alkoxyl and alkyl radicals, which mimic important radical intermediates formed during polyester degradation. This precursor contains glycerol monobenzoate as simplified model for the phthalate structures typically seen in polyesters, and an $\mathrm{N}$-protonated glycine moiety, which acts as a temporary charge tag to enable its isolation in the ion trap of the mass spectrometer (Scheme 2).

Scheme 2. Generation of the Distonic Radical Cations $\mathrm{Oxo}^{+} \mathrm{O}^{\bullet}$ and $\mathrm{Oxo}^{+} \mathrm{C}^{\bullet}$ in the Mass Spectrometer and the IonMolecule Reactions Studied in This Work

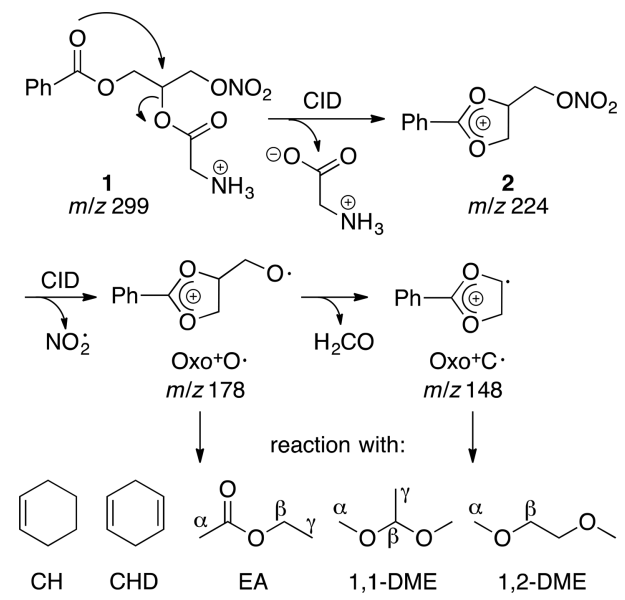

The nitrate group in $\mathbf{1}$ serves as a masked radical site that is unleashed through collision-induced dissociation (CID) of the labile $\mathrm{O}-\mathrm{NO}_{2}$ bond. ${ }^{22,23}$ Upon CID, first loss of glycine occurs through a neighboring group reaction ${ }^{24,25}$ to produce nitrate 2 at $m / z 224$, which features a cyclic tertiary carboxonium ion $^{26-28}$ as the fixed charge tag. A second stage of CID generates the desired alkoxyl radical cation $\mathrm{Oxo}^{+} \mathrm{O}^{\bullet}$ at $m / z 178$. Subsequent $\beta$-fragmentation with elimination of formaldehyde produces the $C$-centered radical cation $\mathrm{Oxo}^{+} \mathrm{C}^{\bullet}$ at $m / z 148$.

The chemistry of $\mathrm{Oxo}^{+} \mathrm{O}^{\bullet}$ and $\mathrm{Oxo}^{+} \mathrm{C}^{\bullet}$ was explored through their ion-molecule reactions with cyclohexene $(\mathrm{CH})$, cyclohexadiene (CHD), ethyl acetate (EA), 1,1-dimethoxyethane
(1,1-DME), and 1,2-dimethoxyethane (1,2-DME), which exhibit important structural features present in both intact and defective polyesters and are sufficiently volatile model systems to be studied in the gas phase. In particular, $\mathrm{CH}$ and CHD provide detailed insight into the reactivity of alkene $\pi$ systems that could be formed through thermal decomposition of polyesters via ester pyrolysis during the manufacturing process. ${ }^{29}$ EA enables exploration of the reactivity of aliphatic ester linkages toward radical damage, whereas 1,1- and 1,2DME represent different glycol motifs. For selected reactions, the experiments were augmented by density functional theory (DFT) calculations of the potential energy surface to identify the regioselectivity.

\section{EXPERIMENTAL METHODS}

Synthesis of Starting Materials. Reactions were monitored using thin layer chromatography (tlc) on commercial silica gel 60 aluminum-backed plates coated with fluorescent indicator F254 (Merck). Plates were visualized using UV light $(254 \mathrm{~nm})$ or in conjunction with ninhydrin-, potassium permanganate-, or phosphomolybdic acid-based stains. Purification by silica gel chromatography was performed using Davisil Chromatographic Silica Media LC60A 40-63 $\mu \mathrm{m}$. NMR spectra were recorded on a Varian INOVA 400 instrument, with operating frequencies of $400 \mathrm{MHz}$ for ${ }^{1} \mathrm{H}$ NMR and $101 \mathrm{MHz}$ for ${ }^{13} \mathrm{C}$ NMR. Chemical shifts $(\delta)$ are in ppm, with residual undeuterated solvent peaks used as an internal reference. High resolution mass spectra (HRMS) were collected via electrospray ionization (ESI) mass spectrometry, using either a Thermo Scientific Exactive Plus Orbitrap mass spectrometer or a Thermo hybrid LTQ-FTICR mass spectrometer (Thermo Scientific, Bremen, Germany).

The precursor 1 was synthesized as trifluoroacetate (TFA) salt according to Scheme 3. The NMR spectra are shown in the Supporting Information (SI).

1-Benzoyl-3-bromo-rac-glycerol (6). The procedure reported by Dawe et al. ${ }^{30}$ was followed to synthesize $\mathrm{Li}_{2} \mathrm{NiBr}_{4}$

Scheme 3. Synthesis of the Distonic Radical Cation Precursor 1

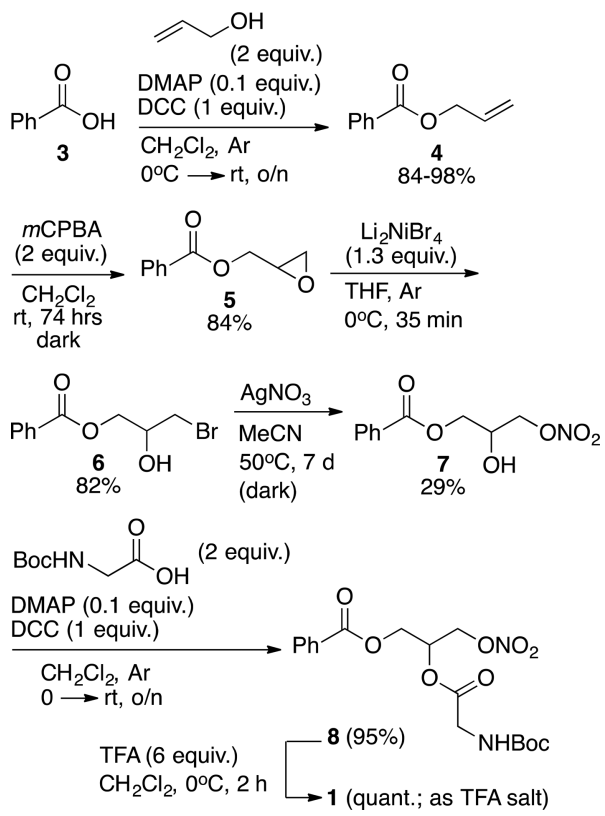


as a $0.4 \mathrm{M}$ solution in tetrahydrofuran. Epoxide $5^{31}(24 \mathrm{mmol})$ was dissolved in tetrahydrofuran $(71 \mathrm{~mL})$ under nitrogen and cooled to $0{ }^{\circ} \mathrm{C}$, followed by dropwise addition of the $\mathrm{Li}_{2} \mathrm{NiBr}_{4}$ solution $(76 \mathrm{~mL}, \sim 30 \mathrm{mmol})$. Consumption of the epoxide was monitored by tlc and complete after $35 \mathrm{~min}$. The reaction mixture was then treated with phosphate buffer $(110 \mathrm{~mL}, \mathrm{pH}$ 7 ) and extracted with dichloromethane, dried, and concentrated in vacuo. The crude product was purified by column chromatography (petroleum spirits/ethyl acetate $3: 1, R_{\mathrm{f}}=$ $0.34)$ to provide 6 as a white powder (82\%). ${ }^{1} \mathrm{H}$ NMR (400 $\left.\mathrm{MHz}, \mathrm{CDCl}_{3}\right): \delta=8.08-8.02(\mathrm{~m}, 2 \mathrm{H}), 7.62-7.56(\mathrm{~m}, 1 \mathrm{H})$, 7.49-7.42 (m, 2H), 4.53-4.43 (m, 2H), $4.21(\mathrm{~m}, 1 \mathrm{H}), 3.61$ (dd, $\left.{ }^{3} J=10.5,4.9 \mathrm{~Hz}, 1 \mathrm{H}\right), 3.55\left(\mathrm{dd},{ }^{3} \mathrm{~J}=10.6,5.9 \mathrm{~Hz}, 1 \mathrm{H}\right)$, $2.66(\mathrm{~s}, 1 \mathrm{H}) .{ }^{13} \mathrm{C} \mathrm{NMR}\left(101 \mathrm{MHz}, \mathrm{CDCl}_{3}\right): \delta=166.58$, $133.40,129.72,129.43,128.49,69.41,66.32,35.08$. HRMS (ESI, $m / z):[\mathrm{M}+\mathrm{H}]^{+}$calcd for $\mathrm{C}_{10} \mathrm{H}_{12} \mathrm{O}_{3} \mathrm{Br}, 258.99643$ and 260.99448; found 258.99639 and 260.99436.

2-Hydroxy-3-nitrooxypropyl Benzoate (7). Compound 6 $(6.5 \mathrm{mmol})$ was suspended in dry acetonitrile $(12 \mathrm{~mL})$ under nitrogen along with silver nitrate $(12 \mathrm{mmol})$. The mixture was kept at $50{ }^{\circ} \mathrm{C}$ in the dark for $7 \mathrm{~d}$, with regular filtration to remove the silver bromide precipitate. Once complete, the mixture was cooled to room temperature and filtered into saturated brine $(40 \mathrm{~mL})$. The resulting silver chloride precipitate was separated and the filtrate extracted with ethyl acetate, dried (magnesium sulfate), and concentrated in vacuo. The crude material was purified by column chromatography (petroleum spirits/ethyl acetate $1: 1, R_{\mathrm{f}}=0.65$ ) to provide 7 as a waxy solid (29\%). ${ }^{1} \mathrm{H} \mathrm{NMR}\left(400 \mathrm{MHz}, \mathrm{CDCl}_{3}\right): \delta=8.07-7.96$ (m, 2H), 7.63-7.53 (m, 1H), 7.49-7.40 (m, 2H), 5.42-5.36 $(\mathrm{m}, 1 \mathrm{H}), 4.87\left(\mathrm{ddd},{ }^{3} \mathrm{~J}=12.3,3.7,0.6 \mathrm{~Hz}, 1 \mathrm{H}\right), 4.78\left(\mathrm{ddd},{ }^{3} \mathrm{~J}=\right.$ $12.4,6.4,0.6 \mathrm{~Hz}, 1 \mathrm{H}), 3.99-3.93(\mathrm{~m}, 1 \mathrm{H}), 3.93-3.87(\mathrm{~m}, 1 \mathrm{H})$, $2.26(\mathrm{~s}, 1 \mathrm{H}) .{ }^{13} \mathrm{C}$ NMR (101 MHz, $\left.\mathrm{CDCl}_{3}\right): \delta=165.87$, 133.57, 129.79, 129.15, 128.50, 71.27, 70.66, 61.20. HRMS (ESI, $m / z):[\mathrm{M}+\mathrm{H}]^{+}$calcd for $\mathrm{C}_{10} \mathrm{H}_{12} \mathrm{NO}_{6}, 242.06591$; found 242.06586; $[\mathrm{M}+\mathrm{Na}]^{+}$calcd for $\mathrm{C}_{10} \mathrm{H}_{11} \mathrm{NO}_{6} \mathrm{Na}$, 264.04786; found 264.04802 .

2-(2-(tert-Butoxycarbonylamino)acetoxy)-3-nitrooxypropyl Benzoate (8). Compound 8 was synthesized from 7 (1 equiv), $N$-Boc-protected glycine (1.5 equiv), dimethylaminopyridine (DMAP; 0.1 equiv), and $N, N$-dicyclohexylcarbodiimide (DCC; 1.5 equiv), following the "General Esterification Procedure" (see SI). Compound $\mathbf{8}$ was obtained as a white solid (95\%), which was used without further purification. ${ }^{1} \mathrm{H}$ NMR $\left(400 \mathrm{MHz}, \mathrm{CDCl}_{3}\right): \delta=8.05-7.98(\mathrm{~m}, 2 \mathrm{H}), 7.63-7.56(\mathrm{~m}$, $1 \mathrm{H}), 7.51-7.42(\mathrm{~m}, 2 \mathrm{H}), 5.52\left(\mathrm{p},{ }^{3} \mathrm{~J}=4.9 \mathrm{~Hz}, 1 \mathrm{H}\right), 4.98(\mathrm{~s}$, $1 \mathrm{H}), 4.82\left(\mathrm{dd},{ }^{3} \mathrm{~J}=12.5,3.8 \mathrm{~Hz}, 1 \mathrm{H}\right), 4.69-4.62(\mathrm{~m}, 1 \mathrm{H})$, $4.62-4.56(\mathrm{~m}, 1 \mathrm{H}), 4.46\left(\mathrm{dd},{ }^{3} J=12.2,5.3 \mathrm{~Hz}, 1 \mathrm{H}\right), 3.97\left(\mathrm{~d},{ }^{3} \mathrm{~J}\right.$ $=5.8 \mathrm{~Hz}, 2 \mathrm{H}), 1.44(\mathrm{~s}, 9 \mathrm{H}) .{ }^{13} \mathrm{C} \mathrm{NMR}\left(101 \mathrm{MHz} \mathrm{CDCl}_{3}\right): \delta=$ $165.86,157.38155 .55,133.55,129.73,129.04,128.57,79.66$, 70.12, 68.74, 62.08, 42.33, 28.25. HRMS (ESI, $m / z):[\mathrm{M}+\mathrm{H}]^{+}$ calcd for $\mathrm{C}_{17} \mathrm{H}_{23} \mathrm{~N}_{2} \mathrm{O}_{9}, 399.13981$; found 399.13973; $[\mathrm{M}+$ $\mathrm{Na}]^{+}$calcd for $\mathrm{C}_{17} \mathrm{H}_{22} \mathrm{~N}_{2} \mathrm{O}_{9} \mathrm{Na}$, 421.12175; found 421.12177.

2-(1-Benzoyloxy-3-nitrooxy)propan-2-yloxy-2-oxoethanaminium (1). Compound 8 was dissolved in dichloromethane at room temperature and cooled to $0{ }^{\circ} \mathrm{C}$. With stirring, trifluoroacetic acid (TFA; 6 equiv) was added dropwise, and the mixture was stirred at room temperature and monitored by tlc. When consumption of $\mathbf{8}$ was complete, the solvent was evaporated under vacuum, using toluene as an azeotrope to remove any remaining acid. The resulting TFA salt was directly used in the mass spectrometric experiments without further purification. ${ }^{1} \mathrm{H}$ NMR (400 MHz, DMSO- $\left.d_{6}\right): \delta=8.23(\mathrm{~s}, 3 \mathrm{H})$,
8.01-7.94 (m, 2H), 7.73-7.64 (m, 1H), 7.58-7.49 (m, 2H), 5.59 (ddd, $J=9.7,6.5,3.2 \mathrm{~Hz}, 1 \mathrm{H}), 4.95\left(\mathrm{dd},{ }^{3} J=12.4,3.1 \mathrm{~Hz}\right.$, $1 \mathrm{H}), 4.83\left(\mathrm{dd},{ }^{3} J=12.4,7.0 \mathrm{~Hz}, 1 \mathrm{H}\right), 4.57\left(\mathrm{dd},{ }^{3} \mathrm{~J}=12.2,3.8\right.$ $\mathrm{Hz}, 1 \mathrm{H}$ ), 4.46 (dd, $J=12.3,5.8 \mathrm{~Hz}, 1 \mathrm{H}), 3.90$ (s, 2H). HRMS (ESI, $m / z):[\mathrm{M}+\mathrm{H}]^{+}$calcd for $\mathrm{C}_{12} \mathrm{H}_{15} \mathrm{~N}_{2} \mathrm{O}_{7}, 299.08738$; found 299.08727.

Mass Spectrometric Experiments. Gas-phase studies were conducted on a Thermo Scientific (Bremen, Germany) LTQ ESI mass spectrometer, modified to enable the introduction of volatile neutral reagents into the linear ion trap to perform ion-molecule reactions (IMRs). Briefly, a suitably volatile liquid reagent was injected at a rate of $5-50 \mu \mathrm{L}$ $\mathrm{min}^{-1}$ directly into the helium line supplying helium bath gas to the linear ion trap. The helium line was heated and maintained at a temperature above the boiling point of the reagent, volatilizing the liquid before it reached the ion trap. The pressure regulator controlling the flow of helium into the ion trap under normal operating conditions was bypassed, with the helium pressure controlled manually to maintain an ion gauge pressure the same as under normal operating conditions (0.69 $\times 10^{-5}$ Torr). Further details are given in refs $12,13,32$, and 33. Ions undergoing ion-molecule reactions in the ion trap of the mass spectrometer are quasi thermalized to the temperature of the helium bath gas $(298 \mathrm{~K}) .^{32}$ When performing IMRs, an ion of interest was isolated inside the ion trap, where it could react with the neutral. Each neutral compound used in the IMRs was purified prior to use via distillation, with purity checked by NMR.

General Mass Spectrometer Settings. Compound samples were prepared to $75-100 \mu \mathrm{M}$ in methanol and were injected into the ESI source at a flow rate of $5 \mu \mathrm{L} \min ^{-1}$. The instrument was operated in positive ion mode, with the settings tuned to optimize the signal of the initial parent ion peak at the beginning of each data collection session. ESI source conditions included needle potentials between 2.5 and $4.7 \mathrm{kV}$, a capillary temperature of $250{ }^{\circ} \mathrm{C}$, capillary voltages between 0.0 and 34.0, and tube lens voltages between 0.0 and $55.0 \mathrm{~V}$. The helium bath gas was adjusted to maintain an ion gauge pressure of 0.69 $\times 10^{-5}$ Torr. Ions of interest for $\mathrm{MS}^{\mathrm{n}}$ experiments were isolated with a $2-5 \mathrm{~m} / z$ window. The CID parameter was selected so that the parent ion being fragmented was reduced to $\sim 15 \%$ abundance. Data was collected using three microscans and taking between 10 and 100 replicate spectra.

Kinetic Studies. Absolute rate coefficients for the consumption of $\mathrm{Oxo}^{+} \mathrm{O}^{\bullet} / \mathrm{C}^{\bullet}$ through reaction with the neutrals $\mathrm{CH}, \mathrm{CHD}$, EA, 1,1-DME, and 1,2-DME according to $\mathrm{Oxo}^{+} \mathrm{O}^{\bullet}$ $\mathrm{C}^{\bullet}+$ neutral $\rightarrow$ products, were obtained at $298 \mathrm{~K}$ by monitoring the decay of the $\mathrm{Oxo}^{+} \mathrm{O}^{\bullet} / \mathrm{C}^{\bullet}$ signal at $\mathrm{m} / z 178$ and $m / z 148$, respectively $\left([\mathrm{M}]^{\bullet+}\right)$, as a function of reaction time under pseudo-first order conditions. Four to seven different excess concentrations of the neutral were used on time scales that allowed the peak intensity of $\mathrm{Oxo}^{+} \mathrm{O}^{\bullet} / \mathrm{C}^{\bullet}$ to decrease to ca. $20 \%$ and to build up time-resolved decay profiles (8-17 reaction times). The pseudo-first order rate coefficient $k_{\text {obs }}$ was obtained from the slope of the semilogarithmic plot $\ln \left[\mathrm{Oxo}^{+} \mathrm{O}^{\bullet} / \mathrm{C}^{\bullet}\right]$ vs reaction time. The second-order rate coefficient $k$ was determined by plotting $k_{\text {obs }}$ vs [neutral], see Figure $\mathrm{S} 1$ in the SI. Since the reactions of $\mathrm{Oxo}^{+} \mathrm{O}^{\bullet}$ with both $\mathrm{CHD}$ and 1,2-DME were extremely fast, $k_{\mathrm{obs}}$ could only be obtained for a narrow substrate concentration range. The second order rate coefficients were therefore determined for each concentration-time profile according to $k_{\mathrm{obs}} /[\mathrm{CHD}$ or 1,2-DME], followed by averaging the resulting data. 
The rate coefficients for product formation, i.e., $\mathrm{Oxo}^{+} \mathrm{OH} /$

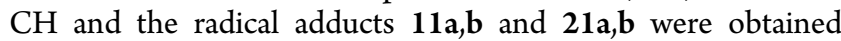
from kinetic modeling of the experimental concentration-time profiles using the program Dynafit $4 .{ }^{34}$ The concentration of the various ionic species was directly reflected by their peak areas, since mass discrimination could be excluded. The pseudo-first order rate coefficients for product formation, $k_{\text {obs }}^{\prime}$, were fitted for the HAT pathway: $\mathrm{Oxo}^{+} \mathrm{O}^{\bullet} / \mathrm{C}^{\bullet}+$ neutral $\rightarrow \mathrm{Oxo}^{+} \mathrm{OH} / \mathrm{CH}+\left[\right.$ neutral- $\mathrm{H}^{\bullet}$, at $m / z 179$ and $\mathrm{m} / \mathrm{z} 149$, respectively, and for the $\mathrm{Oxo}^{+} \mathrm{O}^{\bullet} / \mathrm{C}^{\bullet}$ addition pathway: $\mathrm{Oxo}^{+} \mathrm{O}^{\bullet} / \mathrm{C}^{\bullet}+$ neutral $\rightarrow\left[\mathrm{Oxo}^{+} \mathrm{O}-\text { neutral adduct }\right]^{\bullet}$, at $\mathrm{m} / \mathrm{z}$ 260 (11a) and $\mathrm{m} / \mathrm{z} 258$ (11b); and [Oxo ${ }^{+} \mathrm{C}-$ neutral adduct] ${ }^{\bullet}$ at $\mathrm{m} / \mathrm{z} 230(21 \mathbf{a})$ and $\mathrm{m} / \mathrm{z} 228(21 \mathbf{b})$. The second-order rate coefficient $k^{\prime}$ for formation of each individual product was obtained from plotting $k_{\text {obs }}^{\prime}$ vs [neutral], except for the lowyielding adducts $\mathbf{1 1 b}$ and $\mathbf{2 1 b}$ in the reaction of $\mathrm{CHD}$ with $\mathrm{Oxo}^{+} \mathrm{O}^{\bullet}$ and $\mathrm{Oxo}^{+} \mathrm{C}^{\bullet}$, respectively, where $k^{\prime}$ was determined from the average of the individual concentration-time profiles, i.e., $k_{\text {obs }}^{\prime} /[\mathrm{CHD}]$. It was necessary to extend the kinetic scheme for simulating the rate coefficients for formation of the products $\mathrm{Oxo}^{+} \mathrm{CH}$ and $\left[\mathrm{Oxo}^{+} \mathrm{C}-\text { neutral adduct }\right]^{\bullet}$ by the reaction $\mathrm{Oxo}^{+} \mathrm{C}^{\bullet} \rightarrow \mathrm{PhC} \equiv \mathrm{O}^{+}$, in order to account for the competing unimolecular decomposition of $\mathrm{Oxo}^{+} \mathrm{C}^{\bullet}$. The data are shown in Figures S2-S5 in the SI.

Computational Studies. DFT calculations were carried out utilizing the Gaussian 09 program $^{35}$ at the M062X/6$31+\mathrm{G}^{*}$ level of theory. All ground and transition states were verified by vibrational frequency analysis at the same level of theory, and all identified transition states showed only one imaginary frequency. The spin expectation value, $\left\langle s^{2}\right\rangle$, was very close to 0.75 after spin annihilation. All energies are given as enthalpies, which have been shown to best describe chemical reactivity under low-pressure bimolecular conditions. ${ }^{36}$ We also explored the BHandHLYP/6-31+G* method, but found that it calculates higher energies for the stationary points in these gasphase reactions than $\mathrm{M} 062 \mathrm{X} / 6-31+\mathrm{G}^{*}$. In some cases, the BHandHLYP computed transition states even indicated slow reactions, in contradiction with the experimental findings. The $\mathrm{M} 062 \mathrm{X} / 6-31+\mathrm{G}^{*}$ data were considered sufficiently precise to obtain qualitative information about radical reactivity and selectivity for the different pathways. The Gaussian 09 archive entries for all $\mathrm{M} 062 \mathrm{X} / 6-31+\mathrm{G}^{*}$ optimized ground and transition states are given in the SI.

\section{RESULTS AND DISCUSSION}

1. Mass Spectrometry Experiments. Figure 1 shows the CID mass spectrum of the distonic radical cation precursor 1 (see Experimental Methods for details). As outlined in Scheme 2 , the initial CID process produces nitrate 2 at $\mathrm{m} / z 224$ as the major product, which results from loss of glycine (Figure 1a). DFT calculations revealed that the positive charge in $\mathbf{2}$ is stabilized through formation of a cyclic carboxonium ion, ${ }^{26-28}$ suggesting that the cleavage of the glycine moiety is facilitated by neighboring group effects. ${ }^{24,25}$ Attempts to locate a stable ground state structure with an uncyclized carbocation by DFT were not successful.

Isolation of $\mathbf{2}$ in the ion trap and CID leads to cleavage of the $\mathrm{O}-\mathrm{NO}_{2}$ bond to form the alkoxyl radical $\mathrm{Oxo}^{+} \mathrm{O}^{\bullet}$ at $\mathrm{m} / z 178$ (Figure 1b). Subsequent spontaneous or CID induced fragmentation of $\mathrm{Oxo}^{+} \mathrm{O}^{\bullet}$ produces the carbon-centered radical $\mathrm{Oxo}^{+} \mathrm{C}^{\bullet}(m / z$ 148). In addition to this, fragmentation to the benzoyl cation $\mathrm{PhC} \equiv \mathrm{O}^{+}$at $m / z 105$ also occurred, which likely

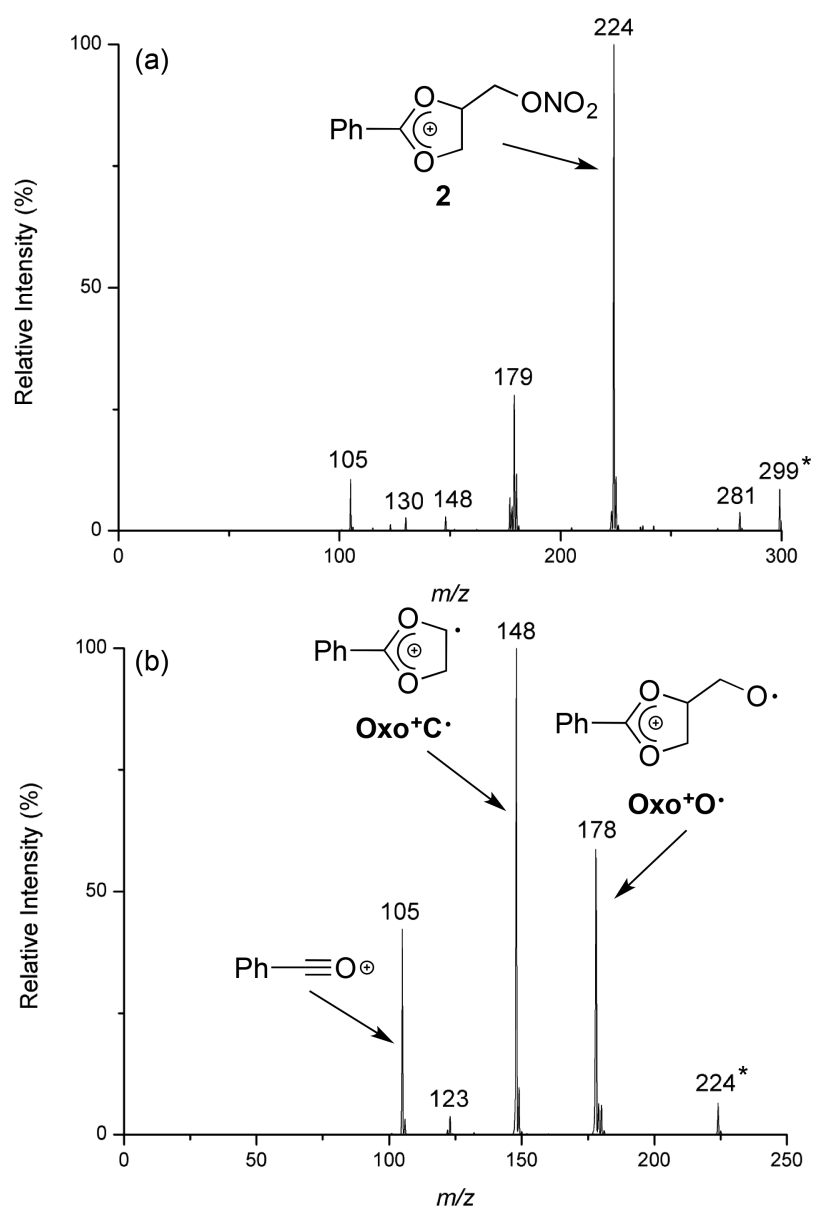

Figure 1. Mass spectra resulting from (a) CID of precursor $1(\mathrm{~m} / \mathrm{z}$ 299) to produce cyclic nitrate 2 at $m / z 224$. (b) CID of 2 leads to the distonic radical cations $\mathrm{Oxo}^{+} \mathrm{O}^{\bullet}\left(\mathrm{m} / z\right.$ 178) and $\mathrm{Oxo}^{+} \mathrm{C}^{\bullet}(\mathrm{m} / z$ 148). The mass-selected precursor ion is indicated by an asterisk $(*)$.

results from a sequential ring-opening/dissociation process in $\mathrm{Oxo}^{+} \mathrm{C}^{\bullet}$ via an intermediate radical cation 9 (Scheme 4).

Scheme 4. Proposed Mechanism of Formation of $\mathrm{PhC} \equiv \mathrm{O}^{+}$ at $m / z 105$ through Ring-Opening/Fragmentation of $\mathrm{Oxo}^{+} \mathrm{C}^{\bullet}$

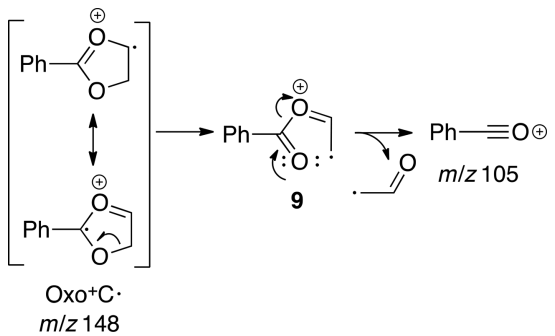

The minor product at $m / z 123$ in Figure $1 \mathrm{~b}$ could result from a secondary reaction of $\mathrm{PhC} \equiv \mathrm{O}^{+}$with residual water present in the ion trap, in particular, since CID of the isolated $\mathrm{m} / z 123$ species produced only $\mathrm{PhC} \equiv \mathrm{O}^{+}$. However, isolation of $\mathrm{PhC} \equiv$ $\mathrm{O}^{+}$in the ion trap revealed no reaction even after an exposure time of ten seconds, which suggests that $m / z 123$ is a direct fragmentation product.

The site of the unpaired electron in $\mathrm{Oxo}^{+} \mathrm{O}^{\bullet}$ and $\mathrm{Oxo}^{+} \mathrm{C}^{\bullet}$ was confirmed by mass spectrometry through their reaction with $\mathrm{O}_{2}$, using helium bath gas that contained $0.001 \% \mathrm{O}_{2}$. Reaction 
with $\mathrm{Oxo}^{+} \mathrm{O}^{\bullet}$ led to formation of a product at $\mathrm{m} / z 177$ in accordance with aldehyde 10 , which results from abstraction of a $\alpha$-hydrogen atom (Scheme 5). ${ }^{37}$

Scheme 5. Experimental and Computational Analysis of the Location of the Unpaired Spin and Charge in $\mathrm{Oxo}^{+} \mathrm{O}^{\bullet}$ and $\mathrm{Oxo}^{+} \mathrm{C}^{\bullet a}$

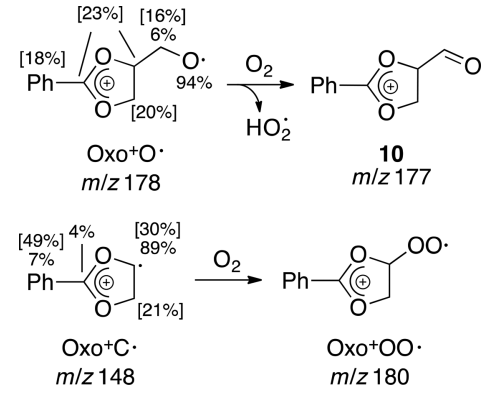

${ }^{a}$ Spin densities and charges (in square brackets) calculated with $\mathrm{M} 062 \mathrm{X} / 6-31+\mathrm{G}^{*}$.

The reaction of $\mathrm{Oxo}^{+} \mathrm{C}^{\bullet}$ with $\mathrm{O}_{2}$ led to a new product with $m / z 180$, which can be assigned to the peroxyl radical cation $\mathrm{Oxo}^{+} \mathrm{OO} \cdot{ }^{12,13,16-18,21}$ In fact, in some systems studied in this work secondary reactions involving $\mathrm{Oxo}^{+} \mathrm{OO}^{\bullet}$ also occurred. We will report on the chemistry of such aliphatic distonic peroxyl radical cations in a separate paper.

According to DFT calculations (see below), the unpaired electron in $\mathrm{Oxo}^{+} \mathrm{O}^{\bullet}$ is located practically exclusively (94\%) on the oxygen atom, confirming its nature as O-centered radical. The spin density in $\mathrm{Oxo}^{+} \mathrm{C}^{\bullet}$ is also predominantly (89\%) located on the expected carbon atom with some delocalization onto the benzylic carbon atom and the phenyl ring. Analysis of the Mulliken charges further revealed that charge and spin are not fully separated and that the radical center in $\mathrm{Oxo}^{+} \mathrm{C}^{\bullet}$ and the carbon atom adjacent to the radical center in $\mathrm{Oxo}^{+} \mathrm{O}^{\bullet}$ exhibit a partial positive charge.

It should be noted that we have also designed and synthesized a series of other precursor molecules structurally related to 1 , but in the mass spectrometer none of these underwent $\mathrm{CID}$ to produce distonic $\mathrm{O}$ - and $\mathrm{C}$-centered radical cations (see SI for details). This shows that seemingly small structural differences have a profound and difficult-to-predict impact on the molecule's behavior upon CID, making the design of suitable radical precursors a challenge.

1.1. Ion-Molecule Reactions with $\mathrm{OxO}^{+} \mathrm{O}^{\circ}$. The reaction of $\mathrm{Oxo}^{+} \mathrm{O}^{\bullet}$ with $\mathrm{CH}$ was found to be very fast with the peak intensity dropping to $\sim 20 \%$ after a maximum of $400 \mathrm{~ms}$. The major pathway occurs through HAT, likely from the allylic $\mathrm{CH}_{2}$ moiety, to give $\mathrm{Oxo}^{+} \mathrm{OH}$ at $m / z 179$ (Figure 2a). The corresponding $\alpha$-cyclohexenyl radical (not shown) is not charged and cannot be detected.

Minor formation of the addition product between $\mathrm{Oxo}^{+} \mathrm{O}^{\bullet}$ and $\mathrm{CH}$ at $\mathrm{m} / z 260$ (i.e., 11a) also occurred. The finding that aliphatic alkoxyl radicals react with alkenes with high preference through allylic HAT, rather than by addition to the $\pi$ system, is consistent with literature data ${ }^{38,39}$ and verifies our experimental setup.

Due to the presence of highly activated bis-allylic $\mathrm{C}-\mathrm{H}$ bonds, the reaction of $\mathrm{Oxo}^{+} \mathrm{O}^{-}$with $\mathrm{CHD}$ was extremely fast, and only low excess $[\mathrm{CHD}]$ was required for the reaction to be completed on a millisecond time scale. $\mathrm{Oxo}{ }^{+} \mathrm{OH}$ was formed as
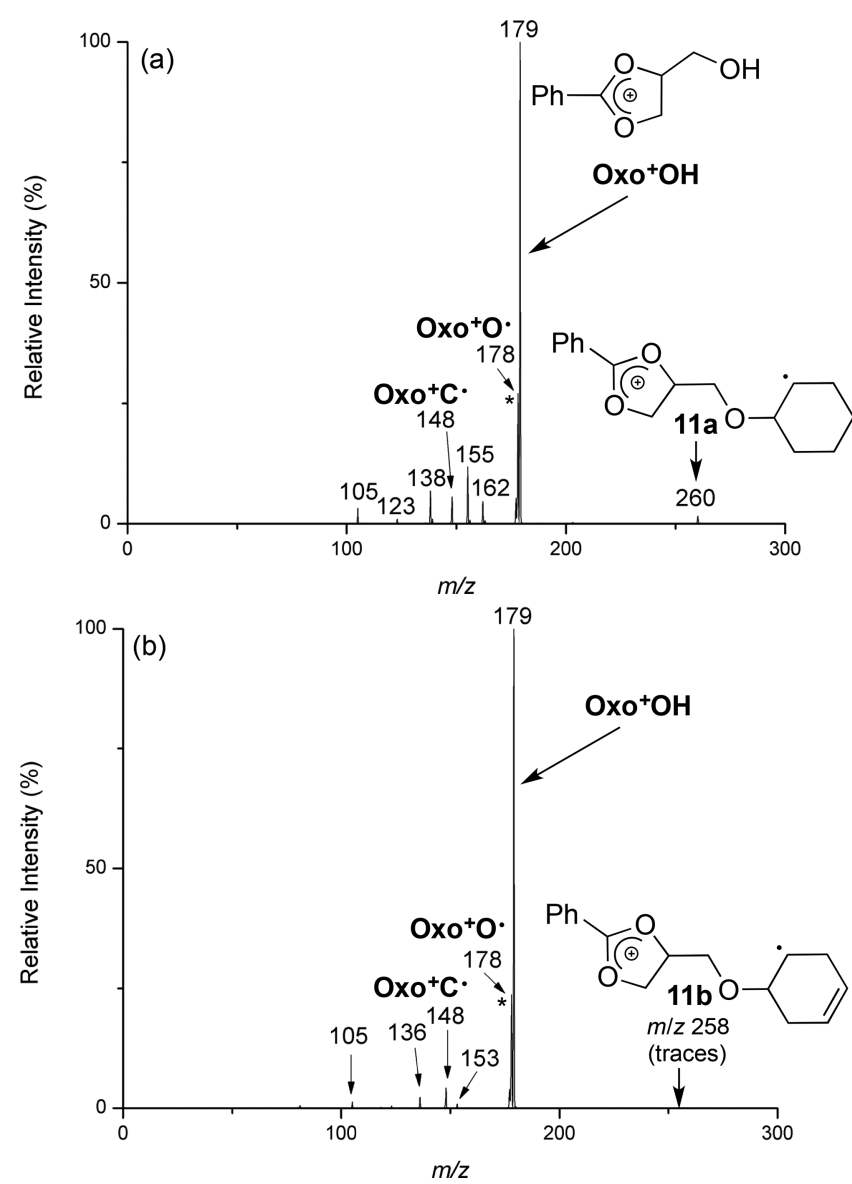

Figure 2. Mass spectrum of the reaction of $\mathrm{Oxo}^{+} \mathrm{O}^{\bullet}$ with (a) $\mathrm{CH}$ after $280 \mathrm{~ms}\left([\mathrm{CH}]\right.$ ca. $7.0 \times 10^{9}$ molecules $\left.\mathrm{cm}^{-3}\right)$ and with (b) CHD after $180 \mathrm{~ms}\left([\mathrm{CHD}]\right.$ ca. $2.5 \times 10^{9}$ molecules $\left.\mathrm{cm}^{-3}\right)$. The mass-selected precursor ion is indicated by an asterisk $(*)$.

the major product (Figure $2 b$ ), whereas only trace amounts of the adduct $11 \mathbf{b}$ (at $m / z 258$ ) resulting from addition of $\mathrm{Oxo}^{+} \mathrm{O}^{\bullet}$ to one of the $\pi$ systems in CHD were observed.

In the $\mathrm{Oxo}^{+} \mathrm{O}^{\bullet}$ reactions with both $\mathrm{CH}$ and $\mathrm{CHD}$ formation of small amounts of byproducts at $\mathrm{m} / z 148$ and $\mathrm{m} / z 105$ also occurred, which result from the competing unimolecular decay of $\mathrm{Oxo}^{+} \mathrm{O}^{\bullet}$ (see Figure $1 \mathrm{~b}$ ).

The minor byproducts at $m / z 155$ and $m / z 138$ in the reaction involving $\mathrm{CH}$ and their lighter analogues in the reaction with $\mathrm{CHD}(\mathrm{m} / z 153$ and $\mathrm{m} / z$ 136) are likely formed through fragmentation of the radical adducts $11 \mathrm{a}$ and $11 \mathbf{b}$, respectively, which confirms that $\mathrm{Oxo}^{+} \mathrm{O}^{\bullet}$ addition to the $\pi$ system in $\mathrm{CHD}$ indeed occurs, but only as a very minor pathway. Scheme 6 proposes a possible mechanism initiated by 1,6- or 1,5-HAT, which transfers the radical site onto the carboxonium moiety to give 12 and 17 , respectively. Homolytic fragmentation leads to the respective isomeric radical cations $13^{\prime}$ and $18^{\prime}$. Compound $13^{\prime}$ can undergo a homolytic dissociation (pathway (a)) to release the vinyloxy cation 15 at $\mathrm{m} / \mathrm{z} 153 / 155$ and acyl radical 14. Heterolytic cleavage (pathway (b)) leads to radical $\mathbf{1 6}$ and $\mathrm{PhC} \equiv \mathrm{O}^{+}$. Radical cation $1 \mathbf{8}^{\prime}$ could rearrange through 1,5-HAT from the cyclohex $(\mathrm{en}) \mathrm{yl}$ ring to give 19 , followed by heterolytic fragmentation into benzoic acid and the cationic radical fragment 20 at $\mathrm{m} / z$ 138/ 136. Thus, although formation of the $C$-centered radical adducts $1 \mathbf{1 a} / \mathbf{b}$ are only minor pathways in the reaction of $\mathrm{Oxo}^{+} \mathrm{O}^{\bullet}$ with $\mathrm{CH}$ and $\mathrm{CHD}$, our findings clearly show that such 
Scheme 6. Proposed Mechanism for Formation of the ByProducts at $m / z 155 / 153$ and $m / z 138 / 136$ in the Reactions of $\mathrm{Oxo}^{+} \mathrm{O}^{\bullet}$ with $\mathrm{CH}$ and $\mathrm{CHD}$
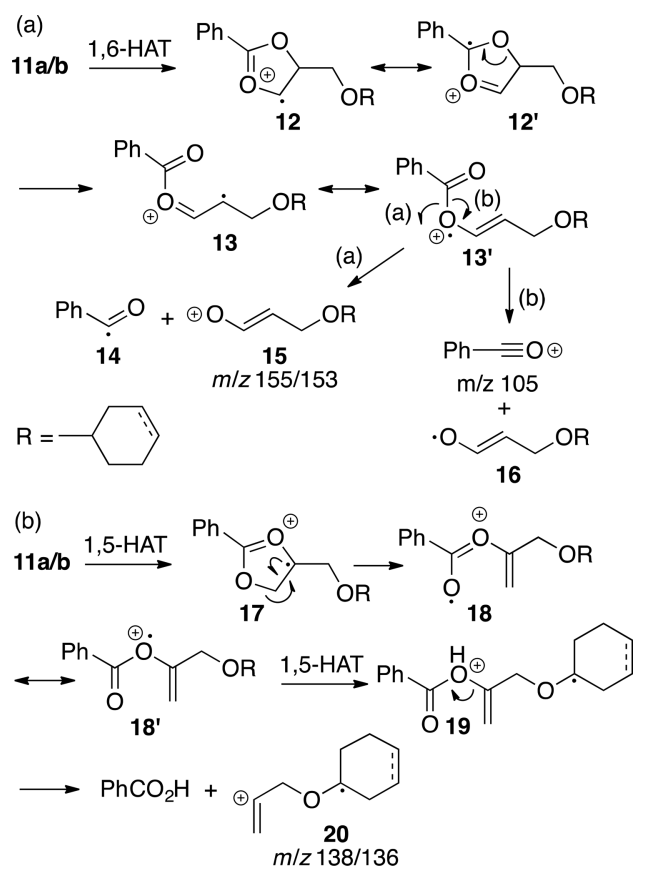

intermediates rapidly propagate radical damage through rearrangement and fragmentation processes.

The reaction of $\mathrm{Oxo}^{+} \mathrm{O}^{\bullet}$ with EA was considerably slower and required monitoring on the seconds time scale for the $\mathrm{Oxo}^{+} \mathrm{O}^{\bullet}$ signal to decrease to $\sim 20 \%$. Formation of $\mathrm{Oxo}^{+} \mathrm{OH}$ was the major pathway (Figure 3a), but with increasing reaction time the competing unimolecular decay $\mathrm{Oxo}^{+} \mathrm{O}^{\bullet} \rightarrow \mathrm{Oxo}^{+} \mathrm{C}^{\bullet}$ became significant, as shown in the concentration/time profiles in Figure $3 \mathrm{~b}$. As will be outlined below, the product ion at $\mathrm{m} / z$ 177 results from the secondary reaction of $\mathrm{Oxo}^{+} \mathrm{C}^{\bullet}$ with EA.

In contrast to this, the reaction of $\mathrm{Oxo}^{+} \mathrm{O}^{\bullet}$ with $1,1-\mathrm{DME}$ was very fast and required only about $450 \mathrm{~ms}$ for the $\mathrm{Oxo}^{+} \mathrm{O}^{\bullet}$ signal to drop to $\sim 20 \%$. Formation of $\mathrm{Oxo}^{+} \mathrm{OH}$ was identified as the major pathway (see Figure S6). The reaction of $\mathrm{Oxo}^{+} \mathrm{O}^{\bullet}$ with 1,2-DME was even faster, and the $\mathrm{Oxo}^{+} \mathrm{O}^{\bullet}$ signal dropped to $<20 \%$ in less than $150 \mathrm{~ms}$ at the lowest experimentally possible excess $[1,2-\mathrm{DME}]$. $\mathrm{Oxo}^{+} \mathrm{OH}$ was the only product (see Figure S7). These findings clearly demonstrate the high susceptibility of aliphatic ethers to damage by alkoxyl radicals. The regioselectivity in the reactions with EA, 1,1-DME, and 1,2-DME was identified using computational studies, which will be discussed in section 2 .

We also determined the absolute rate coefficients for the various ion-molecules reactions of $\mathrm{Oxo}^{+} \mathrm{O}^{\bullet}$, which are compiled in Table 1 (see Experimental Methods for details).

The rate data determined for the consumption of $\mathrm{Oxo}^{+} \mathrm{O}^{\bullet}$ confirm its high reactivity, in particular with $\mathrm{CHD}$ and 1,2DME, which are about 30 times higher than for EA, the least reactive substrate explored in this study. The rate coefficient for the reaction with $\mathrm{CH}$ is one order of magnitude lower than with CHD. This difference in reactivity can be rationalized by the presence of four bis-allylic hydrogen atoms in $\mathrm{CHD}$, which are highly susceptible for HAT. Comparison of the kinetic data for product formation in the reaction of $\mathrm{CHD}$ revealed similar rate coefficients for $\mathrm{Oxo}^{+} \mathrm{OH}$ formation and $\mathrm{Oxo}^{+} \mathrm{O}^{\bullet}$ consumption, clearly confirming that HAT is the dominant

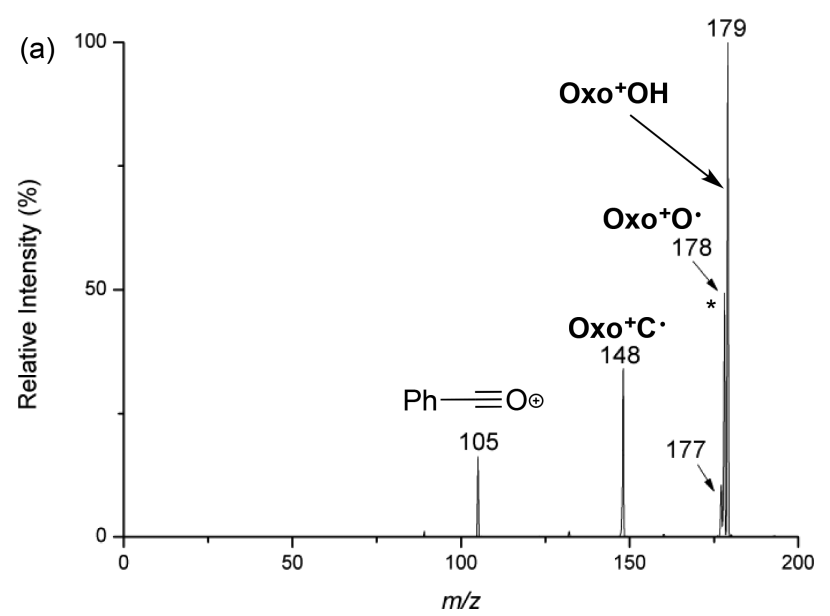

(b)

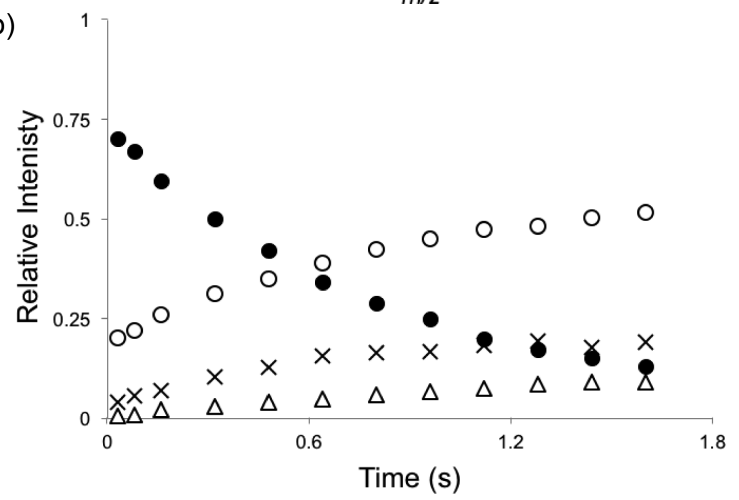

Figure 3. Reaction of $\mathrm{Oxo}^{+} \mathrm{O}^{\bullet}$ with EA ([EA] ca. $7.6 \times 10^{9}$ molecules $\mathrm{cm}^{-3}$ ). (a) Mass spectrum after $960 \mathrm{~ms}$; the mass-selected precursor ion is indicated by an asterisk $(*)$. (b) Concentration-time profile for $\mathrm{Oxo}^{+} \mathrm{O}^{\bullet}(\bullet, m / \mathrm{z}=178), \mathrm{Oxo}^{+} \mathrm{OH}(\mathrm{O}, m / \mathrm{z}=179), \mathrm{Oxo}^{+} \mathrm{C}^{\bullet}(\times, m / \mathrm{z}$ $=148)$, and $\mathrm{PhC} \equiv \mathrm{O}^{+}(\Delta, m / \mathrm{z}=105)$.

pathway $\left(k_{\mathrm{HAT}} / k_{\mathrm{add}} \approx 170\right)$. In contrast to this, radical addition is considerably more favorable in the reaction of $\mathrm{Oxo}^{+} \mathrm{O}^{\bullet}$ with $\mathrm{CH}$, as revealed by the ratio of $k_{\mathrm{HAT}} / k_{\mathrm{add}} \approx 15$. The rate coefficients for $\mathrm{Oxo}^{+} \mathrm{O}^{\bullet}$ consumption and $\mathrm{Oxo}{ }^{+} \mathrm{OH}$ formation in the reactions involving 1,1-DME and 1,2-DME are, within error, the same. This shows that HAT is the exclusive reaction, in agreement with the findings from the product studies. The slightly lower rate coefficient for $\mathrm{Oxo}^{+} \mathrm{OH}$ formation compared to $\mathrm{Oxo}^{+} \mathrm{O}^{\bullet}$ decay in the comparably slow reaction with EA can be rationalized by the fact that unimolecular fragmentation in $\mathrm{Oxo}^{+} \mathrm{O}^{\bullet}$ became a competitive pathway. Overall, the excellent agreement between the rate data for $\mathrm{Oxo}^{+} \mathrm{O}^{\bullet}$ consumption and product formation in all reactions provide evidence that there are no unidentified major sinks for $\mathrm{Oxo}^{+} \mathrm{O}^{\bullet}$, for example, through fragmentation with loss of the permanent charge tag, which would render these products "invisible" by mass spectrometry.

1.2. Ion-Molecule Reactions with $\mathrm{OxO}^{+} \mathrm{C}^{\bullet}$. $\mathrm{Oxo}^{+} \mathrm{C}^{\bullet}$ was considerably less reactive in its bimolecular reactions than $\mathrm{Oxo}^{+} \mathrm{O}^{\bullet}$, and monitoring on the time scale of several seconds was required for the $\mathrm{Oxo}^{+} \mathrm{C}^{\bullet}$ signal to drop to $\sim 20 \%$. Under these conditions the fragmentation to $\mathrm{PhC} \equiv \mathrm{O}^{+}$(see Scheme 4) became an important side reaction.

In the reaction of $\mathrm{Oxo}^{+} \mathrm{C}^{\bullet}$ with $\mathrm{CH}$ the HAT product $\mathrm{Oxo}^{+} \mathrm{CH}($ at $m / z 149)$ and the radical adduct 21a (at $\left.m / z 230\right)$ were both obtained as major products (Figure 4a). However, the most abundant species at $\mathrm{m} / z 187$ could be assigned to the adduct 22a, which was formed through electrophilic addition of 
Table 1. Absolute Second-Order Rate Coefficients $k$ for the Reaction of $\mathrm{Oxo}^{+} \mathrm{O}^{\bullet}$ with the Neutral Model Systems at $298 \mathrm{~K}^{a, b}$

\begin{tabular}{llll} 
& & $k\left(\mathrm{~cm}^{3}\right.$ molecule $\left.{ }^{-1} \mathrm{~s}^{-1}\right)$ & Oxo $^{+} \mathrm{O}^{\bullet}$ addition \\
\cline { 2 - 4 } $\mathrm{CH}$ & Oxo $^{+} \mathrm{O}^{\bullet}$ consumption & Oxo $^{+} \mathrm{OH}$ formation & $(1.1 \pm 0.3) \times 10^{-11 c}$ \\
$\mathrm{CHD}$ & $(3.0 \pm 0.8) \times 10^{-10}$ & $(1.7 \pm 0.4) \times 10^{-10}$ & $(7.0 \pm 2.1) \times 10^{-12 e}$ \\
$\mathrm{EA}$ & $(1.5 \pm 0.4) \times 10^{-9}$ & $(1.2 \pm 0.3) \times 10^{-9}$ & $(7.6 \pm 1.9) \times 10^{-11}$ \\
$1,1-\mathrm{DME}$ & $(9.2 \pm 2.3) \times 10^{-11}$ & $(3.4 \pm 0.9) \times 10^{-10}$ & \\
$1,2-\mathrm{DME}^{d}$ & $(4.6 \pm 1.2) \times 10^{-10}$ & $(1.5 \pm 0.4) \times 10^{-9}$ &
\end{tabular}

${ }^{a}$ Rate data for $\mathrm{Oxo}^{+} \mathrm{O}^{\bullet}$ consumption from pseudo-first order measurements; rate data for $\mathrm{Oxo}^{+} \mathrm{OH}$ formation and $\mathrm{Oxo}^{+} \mathrm{O}^{\bullet}$ addition were fitted using the Dynafit 4 program (see Experimental Methods). ${ }^{b}$ Experimental error $(\geq 25 \%)$ included. ${ }^{c}$ Formation of product 11a at $m / z 260 .{ }^{d}$ Determined by averaging $k$ obtained from individual concentration-time profiles (see Experimental Methods). ${ }^{e}$ Formation of product $11 \mathbf{b}$ at $m / z 258$.
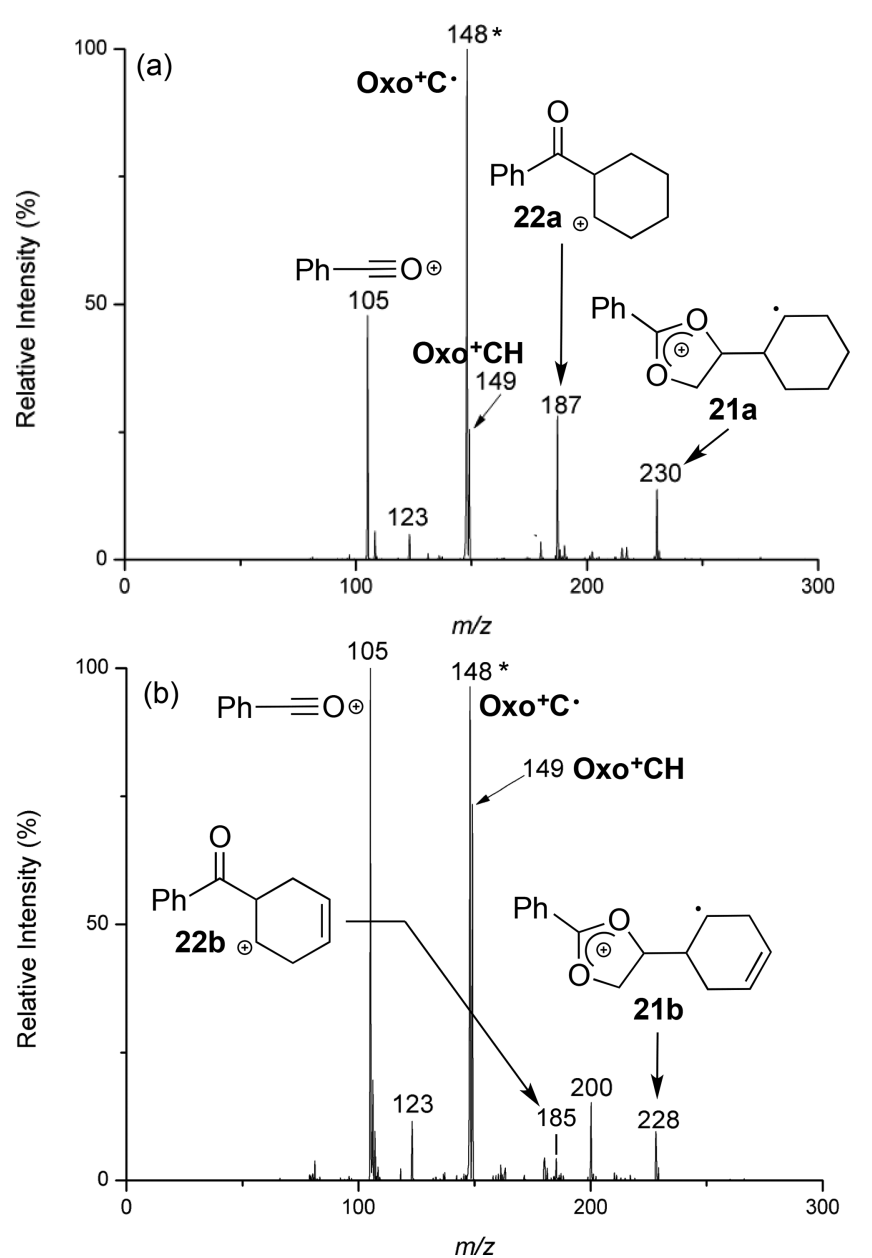

Figure 4. Mass spectrum of the reaction of $\mathrm{Oxo}^{+} \mathrm{C}^{\bullet}$ with (a) $\mathrm{CH}$ after $5000 \mathrm{~ms}\left([\mathrm{CH}]\right.$ ca. $8.7 \times 10^{9}$ molecules $\left.\mathrm{cm}^{-3}\right)$ and with (b) $\mathrm{CHD}$ after $5000 \mathrm{~ms}\left([\mathrm{CHD}]\right.$ ca. $3.3 \times 10^{9}$ molecules $\left.\mathrm{cm}^{-3}\right)$. The massselected precursor ion is indicated by an asterisk $(*)$.

the fragmentation product $\mathrm{PhC} \equiv \mathrm{O}^{+}$to $\mathrm{CH}$. This was confirmed through independent experiments where $\mathrm{PhC} \equiv \mathrm{O}^{+}$ was isolated in the ion trap and reacted with $\mathrm{CH}$.

$\mathrm{Oxo}^{+} \mathrm{CH}$ was also obtained as major product in the reaction of $\mathrm{CHD}$ with $\mathrm{Oxo}^{+} \mathrm{C}^{\bullet}$, due to the higher susceptibility of the bisallylic methylene groups for HAT, whereas radical addition to give the adduct $\mathbf{2 1 b}$ at $\mathrm{m} / z 228$ was less favorable (Figure $4 \mathrm{~b})$. For formation of small amounts of the $\mathrm{CHD}, \mathrm{PhC} \equiv \mathrm{O}^{+}$ adduct $22 \mathbf{b}$ at $m / z 185$ was also observed. No attempts were made to identify the product at $\mathrm{m} / z 200$ since it did not seem to have a "counterpart" in the reaction of $\mathrm{Oxo}^{+} \mathrm{C}^{\bullet}$ with $\mathrm{CH}$.
Interestingly, $\mathrm{Oxo}^{+} \mathrm{C}^{\bullet}$ did not react with EA through HAT to a noticeable extent on the time scale of our experiment. The only significant products were $\mathrm{PhC} \equiv \mathrm{O}^{+}, \mathrm{Oxo}^{+} \mathrm{COO}^{\bullet}(\mathrm{m} / z$ 180; resulting from reaction of $\mathrm{Oxo}^{+} \mathrm{C}^{\bullet}$ with residual $\mathrm{O}_{2}$ in the ion trap) and a product at $\mathrm{m} / z 177$ (Figure 5a).

Trapping experiments of both $\mathrm{PhC} \equiv \mathrm{O}^{+}$and $\mathrm{Oxo}^{+} \mathrm{COO}{ }^{\bullet}$ revealed that the $\mathrm{m} / z 177$ product was not formed through reaction of EA with either of these species. It is therefore suggested that $\mathrm{Oxo}^{+} \mathrm{C}^{\bullet}$ reacts with EA through a homolytic substitution, as shown in Scheme 7, leading to the closed-shell cation 23 and carboxyl radical 24 (which could subsequently decarboxylate). Future studies with isotopically labeled EA will reveal further insight into this unusual radical alkyl transfer reaction.

In contrast to this, $\mathrm{Oxo}^{+} \mathrm{C}^{\bullet}$ reacted readily with $1,1-\mathrm{DME}$ through HAT and formation of $\mathrm{Oxo}^{+} \mathrm{CH}$ (Figure $5 \mathrm{~b}$ ). In addition, small amounts of $\mathrm{Oxo}^{+} \mathrm{COO}^{\bullet}$ were also produced. The notable absence of $\mathrm{PhC} \equiv \mathrm{O}^{+}$could indicate a fast reaction with 1,2-DME that might lead to formation of the products at $m / z 85$ and $m / z 117$, which were not further identified.

The reaction of $\mathrm{Oxo}^{+} \mathrm{C}^{\bullet}$ with 1,2-DME was considerably faster than with the isomeric 1,1-DME and led to $\mathrm{Oxo}^{+} \mathrm{CH}$ as major product (Figure 5c). Additional products resulted from the competing reactions of $\mathrm{Oxo}^{+} \mathrm{C}^{\bullet}$, e.g., the decay to $\mathrm{PhC} \equiv \mathrm{O}^{+}$ and formation of $\mathrm{Oxo}^{+} \mathrm{COO}^{\circ}$. The latter likely underwent a secondary HAT reaction with 1,2-DME to produce the hydroperoxide $\mathrm{Oxo}^{+} \mathrm{COOH}$ at $m / z 181$, which clearly highlights the high susceptibility of ethylene glycol moieties to radical-induced damage.

The decay rate data determined for the $\mathrm{Oxo}^{+} \mathrm{C}^{\bullet}$ reactions with the various neutral model systems are about one to two orders of magnitude lower than for $\mathrm{Oxo}^{+} \mathrm{O}^{\bullet}$ (Table 2). Similar to $\mathrm{Oxo}^{+} \mathrm{O}^{\bullet}$, the fastest rate coefficients were found for $\mathrm{CHD}$ and 1,2-DME, whereas the other neutrals are about ten times less reactive.

The data show a ratio of $k_{\mathrm{HAT}} / k_{\mathrm{add}} \approx 1$ for the reaction of $\mathrm{Oxo}^{+} \mathrm{C}^{\bullet}$ with $\mathrm{CH}$, whereas for the reaction with $\mathrm{CHD}$ the HAT pathway is considerably more favorable $\left(k_{\mathrm{HAT}} / k_{\mathrm{add}} \approx 10\right)$. Similar to $\mathrm{Oxo}^{+} \mathrm{O}^{\bullet}$, the rate coefficients for $\mathrm{Oxo}^{+} \mathrm{C}^{\bullet}$ consumption and $\mathrm{Oxo}^{+} \mathrm{CH}$ formation in the reactions involving 1,1-DME and 1,2-DME, respectively, are the same, confirming that HAT is the exclusive bimolecular reaction pathway for $\mathrm{Oxo}^{+} \mathrm{C}^{\bullet}$.

While the rate coefficient determined from the consumption of $\mathrm{Oxo}^{+} \mathrm{C}^{\bullet}$ in the reaction with EA suggests a fast reaction, this is not reflected by the rate coefficient for $\mathrm{Oxo}^{+} \mathrm{CH}$ formation, which is lower by more than two orders of magnitude (it should be noted that the rate of $\mathrm{Oxo}^{+} \mathrm{CH}$ formation in this reaction, $k_{\mathrm{HAT}}$, is at the low end of our experimental setup and only an upper limit can be given). As outlined in the product 

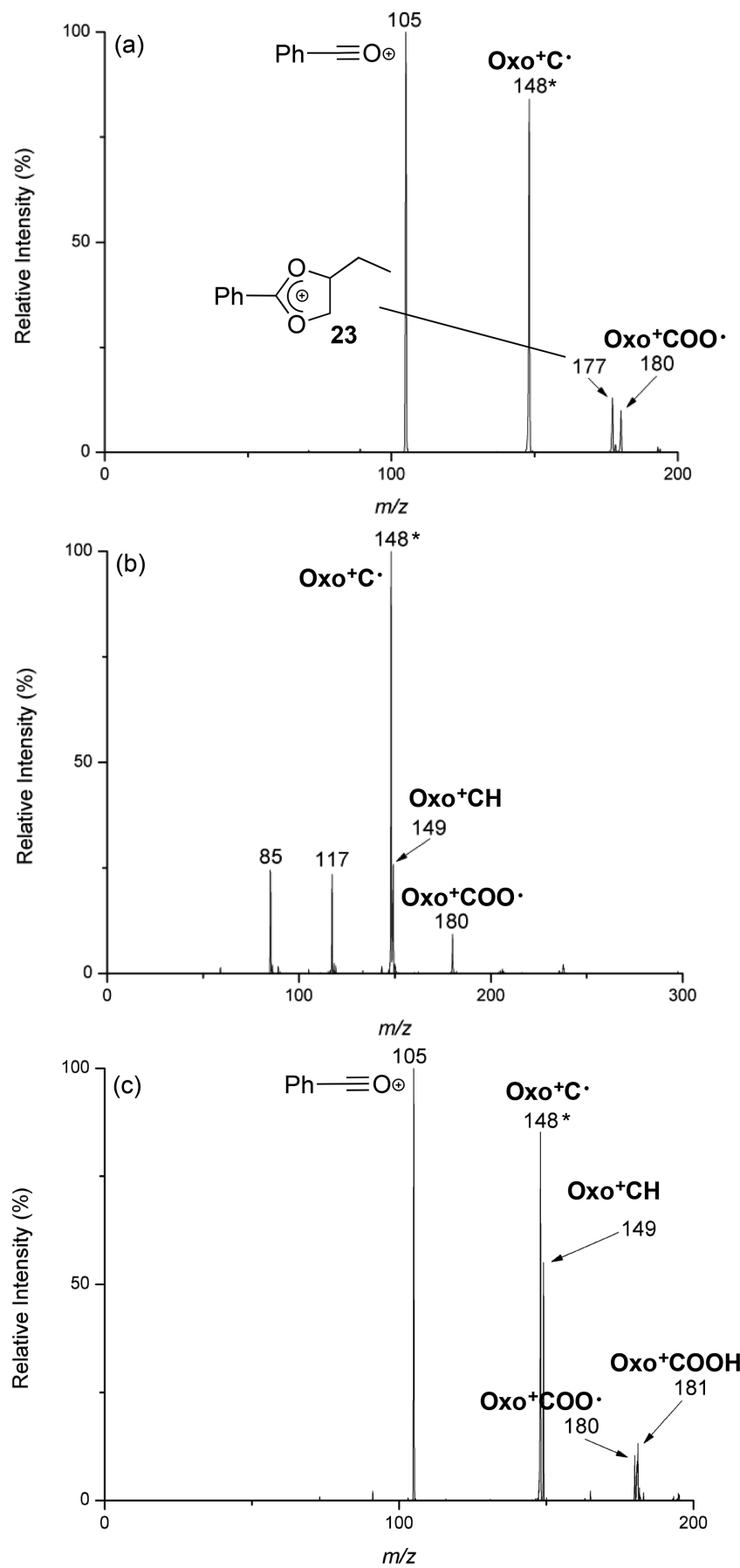

Figure 5. Mass spectrum of the reaction of $\mathrm{Oxo}^{+} \mathrm{C}^{\bullet}$ with (a) EA after $5000 \mathrm{~ms}\left([\mathrm{EA}] \mathrm{ca} .7 .6 \times 10^{9}\right.$ molecules $\mathrm{cm}^{-3}$ ), (b) 1,1-DME after $5000 \mathrm{~ms}\left([1,1-\mathrm{DME}] \mathrm{ca} .7 .1 \times 10^{9}\right.$ molecules $\left.\mathrm{cm}^{-3}\right)$, and (c) 1,2-DME after $5000 \mathrm{~ms}\left([1,2-\mathrm{DME}]\right.$ ca. $5.6 \times 10^{9}$ molecules $\left.\mathrm{cm}^{-3}\right)$. The massselected precursor ion is indicated by an asterisk (*).

Scheme 7. Proposed Mechanism for Formation of the Product at $m / z 177$ in the Reaction of $\mathrm{Oxo}^{+} \mathrm{C}^{\bullet}$ with EA

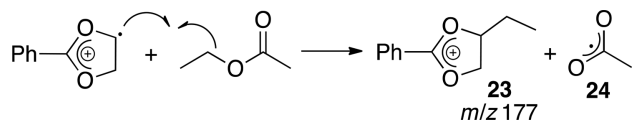

studies, the dominant loss channels for $\mathrm{Oxo}^{+} \mathrm{C}^{\bullet}$ are unimolecular decay to $\mathrm{PhC} \equiv \mathrm{O}^{+}$and formation of the closedshell compound $\mathbf{2 3}$ through an unusual homolytic ethyl transfer from EA, which is much faster than HAT $\left(k_{\mathrm{HAT}} / k_{\text {transfer }}<0.04\right.$; see Table 2).

2. Computational Studies. DFT calculations were carried out to determine the most reactive site for the $\mathrm{Oxo}^{+} \mathrm{O}^{\bullet} / \mathrm{C}^{\bullet}$ induced HAT in EA, 1,1-DME, and 1,2-DME. All reactions proceed through formation of an initial ion-molecule association complex (reactant complex), which is at least 60 $\mathrm{kJ} \mathrm{mol}^{-1}$ lower in energy than the free reactants. The energy of the free reactants, or "entrance channel", will be defined as reference point, which is set to $0 \mathrm{~kJ} \mathrm{~mol}^{-1}$. Due to the low pressure in the ion trap of the mass spectrometer, energy exchange through collisions with the surroundings can be excluded. Thus, the reactant complex has excess energy resulting from the internal and kinetic energy of the free reactants and the electrostatic energy that is released upon complex formation. Any subsequent reaction of the reactant complex is therefore only possible, if the activation barrier for this process is smaller than or equal to the energy difference between the entrance channel and the association complex. ${ }^{40,41}$ Reaction pathways with energies above the entrance channel cannot be accessed.

Generally, the $\mathrm{HAT}$ reactions involving $\mathrm{Oxo}^{+} \mathrm{O}^{\bullet}$ are more exothermic than with $\mathrm{Oxo}^{+} \mathrm{C}^{\bullet}$. Figure 6 shows the calculated potential energy diagram for the reaction of $\mathrm{Oxo}^{+} \mathrm{O}^{\bullet}$ and $\mathrm{Oxo}^{+} \mathrm{C}^{\bullet}$ with EA. HAT from the $\alpha$-, $\beta$-, and $\gamma$-position and formation of the isomeric EA radicals (as product complex with $\mathrm{Oxo}^{+} \mathrm{OH}$ or $\mathrm{Oxo}^{+} \mathrm{CH}$, respectively) is exothermic for both $\mathrm{Oxo}^{+} \mathrm{O}^{\bullet}$ and $\mathrm{Oxo}^{+} \mathrm{C}^{\bullet}$.

The $\alpha$ - and $\beta$-radicals are the thermodynamically preferred products, whereas formation of the $\gamma$-radical is least favorable. HAT from the $\beta$-position is the kinetically preferred pathway for $\mathrm{Oxo}^{+} \mathrm{O}^{\bullet}$, which is associated with an activation barrier of 31 $\mathrm{kJ} \mathrm{mol}^{-1}$. In contrast to this, any of the possible $\mathrm{TS}_{\mathrm{HAT}}$ for the reaction with $\mathrm{Oxo}^{+} \mathrm{C}^{\bullet}$ are located either close to or above the entrance channel, indicating a slow reaction through HAT, in agreement with the experimental data.

The potential energy diagram for the reaction of $\mathrm{Oxo}^{+} \mathrm{O}^{\bullet}$ and $\mathrm{Oxo}^{+} \mathrm{C}^{\bullet}$ with 1,1-DME is shown in Figure 7.

Formation of $\gamma-1,1-\mathrm{DME}$ is thermodynamically least favorable, whereas both $\alpha$ - and $\beta$-1,1-DME are more stable by about $20 \mathrm{~kJ} \mathrm{~mol}^{-1}$ (as product complexes with $\mathrm{Oxo}^{+} \mathrm{OH} /$ $\mathrm{CH})$. Although the energies of the isomeric transition states are low for the reaction with $\mathrm{Oxo}^{+} \mathrm{O}^{\circ}$, overall the $\beta$-HAT is kinetically the most favorable pathway with a barrier of ca. $22 \mathrm{~kJ}$ $\mathrm{mol}^{-1}$. The lower reactivity of $\mathrm{Oxo}^{+} \mathrm{C}^{\bullet}$ leads to a higher selectivity, and a reaction occurs only through $\mathrm{TS}_{\mathrm{HAT}(\alpha)}$ and $\mathrm{TS}_{\mathrm{HAT}(\beta)}$, whereas a pathway via $\mathrm{TS}_{\mathrm{HAT}(\gamma)}$ is energetically not possible.

Figure 8 presents the computed potential energy diagram for the reaction of $\mathrm{Oxo}^{+} \mathrm{O}^{\bullet}$ and $\mathrm{Oxo}^{+} \mathrm{C}^{\bullet}$ with 1,2-DME.

Formation of both $\alpha-1,2-\mathrm{DME}$ and $\beta-1,2-\mathrm{DME}$ (as product complexes with $\mathrm{Oxo}^{+} \mathrm{OH}$ and $\mathrm{Oxo}^{+} \mathrm{CH}$, respectively) is thermodynamically favorable, with the secondary radical $\beta$ 1,2-DME being more stable by about $24 \pm 2 \mathrm{~kJ} \mathrm{~mol}^{-1}$. $\mathrm{Oxo}^{+} \mathrm{O}^{\bullet}$ could abstract hydrogen from both $\alpha$ - and $\beta$-position, which are associated with barriers of ca. $44 \mathrm{~kJ} \mathrm{~mol}^{-1}$ ( $\alpha$ abstraction) and $35 \mathrm{~kJ} \mathrm{~mol}^{-1}$ ( $\beta$ abstraction), respectively. In contrast to this, only $\beta-1,2-\mathrm{DME}$ is formed in the reaction involving $\mathrm{Oxo}^{+} \mathrm{C}^{\bullet}$ since $\mathrm{TS}_{\mathrm{HAT}(\alpha)}$, which leads to $\alpha$-1,2-DME, is located some 23 $\mathrm{kJ} \mathrm{mol}^{-1}$ above the entrance channel and cannot be accessed.

It should be noted that the calculations predict for $\mathrm{Oxo}^{+} \mathrm{O}^{\bullet}$ a faster reaction with 1,1-DME than with 1,2-DME (via the lowest-energy pathway along $\mathrm{TS}_{\mathrm{HAT}(\beta)}$ in both cases), which 
Table 2. Absolute Second-Order Rate Coefficients for the Reaction of Oxo ${ }^{+} \mathrm{C}^{\bullet}$ with the Neutral Model Systems at $298 \mathrm{~K}^{a, b}$

\begin{tabular}{|c|c|c|c|}
\hline \multirow[b]{2}{*}{ neutral } & \multicolumn{3}{|c|}{$k\left(\mathrm{~cm}^{3}\right.$ molecule $\left.{ }^{-1} \mathrm{~s}^{-1}\right)$} \\
\hline & $\mathrm{Oxo}^{+} \mathrm{C}^{\bullet}$ consumption & $\mathrm{Oxo}^{+} \mathrm{CH}$ formation & $\mathrm{Oxo}^{+} \mathrm{C}$ addition \\
\hline $\mathrm{CH}$ & $(7.6 \pm 1.9) \times 10^{-12}$ & $(3.3 \pm 0.8) \times 10^{-12}$ & $(3.3 \pm 0.8) \times 10^{-12 c}$ \\
\hline $\mathrm{CHD}$ & $(3.1 \pm 0.8) \times 10^{-11}$ & $(1.8 \pm 0.4) \times 10^{-11}$ & $(1.9 \pm 1.9) \times 10^{-12 d, e}$ \\
\hline EA & $(5.7 \pm 1.4) \times 10^{-12}$ & $<9 \times 10^{-14}$ & $(2.1 \pm 0.5) \times 10^{-12 f}$ \\
\hline 1,1-DME & $(3.8 \pm 1.0) \times 10^{-12}$ & $(3.5 \pm 0.9) \times 10^{-12}$ & \\
\hline 1,2-DME & $(1.6 \pm 0.4) \times 10^{-11}$ & $(1.4 \pm 0.4) \times 10^{-11}$ & \\
\hline
\end{tabular}

${ }^{a}$ Rate data for $\mathrm{Oxo}^{+} \mathrm{C}^{\bullet}$ consumption from pseudo-first order measurements; rate data for $\mathrm{Oxo}^{+} \mathrm{CH}$ formation and $\mathrm{Oxo}^{+} \mathrm{C}^{\bullet}$ addition were fitted using the Dynafit 4 program (see Experimental Methods). ${ }^{b}$ Experimental error $(\geq 25 \%)$ included. ${ }^{c}$ Formation of product 21 a at $m / z 230 .{ }^{d}$ Determined by averaging $k$ obtained from individual concentration-time profiles (see Experimental Methods). ${ }^{e}$ Formation of product $21 \mathbf{b}$ at $m / z 228 .{ }^{f}$ Formation of product 23 at $\mathrm{m} / \mathrm{z} 177$ (see text).

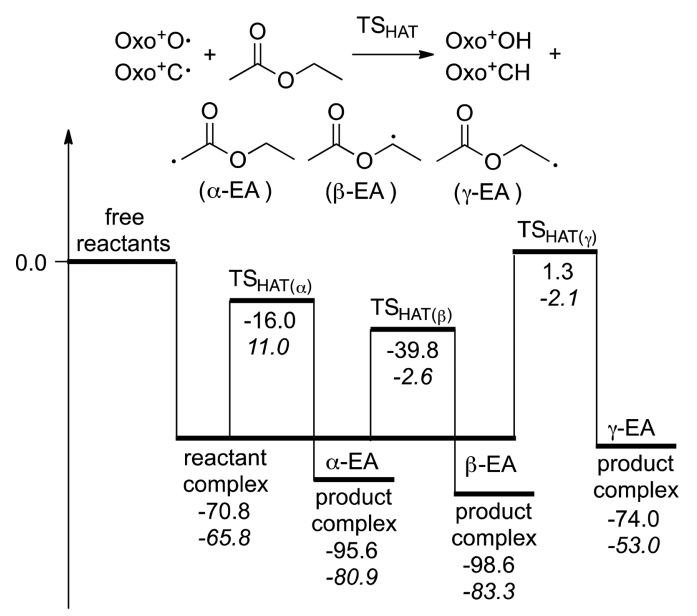

Figure 6. Potential energy diagram for the reaction of $\mathrm{Oxo}^{+} \mathrm{O}^{\bullet}$ and $\mathrm{Oxo}^{+} \mathrm{C}^{\bullet}$ with EA. M062X/6-31+G* enthalpies are in $\mathrm{kJ} \mathrm{mol}^{-1}$ for the reaction involving $\mathrm{Oxo}^{+} \mathrm{O}^{\bullet}$ (normal) and $\mathrm{Oxo}^{+} \mathrm{C}^{\bullet}$ (in italics).

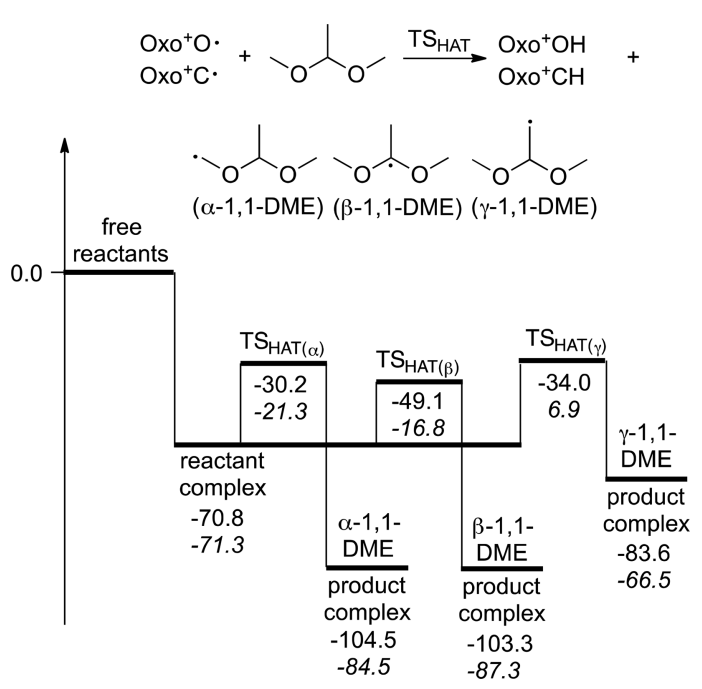

Figure 7. Potential energy diagram for the reaction of $\mathrm{Oxo}^{+} \mathrm{O}^{\bullet}$ and $\mathrm{Oxo}^{+} \mathrm{C}^{\bullet}$ with 1,1-DME. M062X/6-31+G* enthalpies are in $\mathrm{kJ} \mathrm{mol}{ }^{-1}$ for the reaction involving $\mathrm{Oxo}^{+} \mathrm{O}^{\bullet}$ (normal) and $\mathrm{Oxo}^{+} \mathrm{C}^{\bullet}$ (in italics).

seems to contradict the experimental data. However, since 1,1DME possesses only one reactive $\beta$-hydrogen, whereas 1,2 DME has four, the higher rate coefficient determined experimentally for the reaction of $\mathrm{Oxo}^{+} \mathrm{O}^{\bullet}$ with 1,2-DME likely results from a higher probability of successful encounters.

Computational studies were also employed to explore the role of the positive charge tag in $\mathrm{Oxo}^{+} \mathrm{O}^{\bullet} / \mathrm{C}^{\bullet}$ on the radical

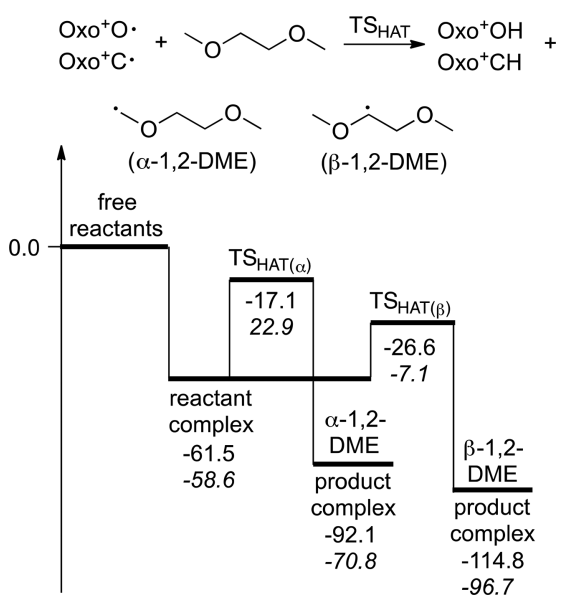

Figure 8. Potential energy diagram for the reaction of $\mathrm{Oxo}^{+} \mathrm{O}^{\bullet}$ and $\mathrm{Oxo}^{+} \mathrm{C}^{\bullet}$ with 1,2-DME. M062X/6-31+G* enthalpies are in $\mathrm{kJ} \mathrm{mol}^{-1}$ for the reaction involving $\mathrm{Oxo}^{+} \mathrm{O}^{\bullet}$ (normal) and $\mathrm{Oxo}^{+} \mathrm{C}^{\bullet}$ (in italics).

reactivity by comparing them with their neutral counterparts $\mathrm{OxoO}^{\bullet} / \mathrm{C}^{\bullet}$, which have a neutral dioxolane instead of the dioxonium ring. Using the reaction with $\mathrm{CH}$ as example, the activation barriers for both allylic HAT and radical addition to the $\pi$ system are about $26-37 \mathrm{~kJ} \mathrm{~mol}^{-1}$ higher for $\mathrm{OxoO} \bullet / \mathrm{C}^{\bullet}$ compared to $\mathrm{Oxo}^{+} \mathrm{O}^{\bullet} / \mathrm{C}^{\bullet}$. The calculations also revealed that the charge tag does not significantly affect the preference for one pathway over the other (data not shown). This confirms that the distonic radical cations studied in this work are excellent model systems for $\mathrm{O}$ - and $\mathrm{C}$-centered polymerderived radicals that enable to study their reactions on the short time scales of ion trap mass spectrometry experiments.

\section{CONCLUSIONS}

A novel precursor (1) to the distonic $\mathrm{O}$ - and $\mathrm{C}$-centered radical cations $\mathrm{Oxo}^{+} \mathrm{O}^{\bullet}$ and $\mathrm{Oxo}^{+} \mathrm{C}^{\bullet}$ was designed and synthesized to provide model systems for radicals produced during polyester degradation. The mass spectrometric studies revealed that reactions involving $\mathrm{Oxo}^{+} \mathrm{O}^{\bullet}$ were extremely fast. Allylic HAT was the predominant reaction pathway with $\mathrm{CH}$ and $\mathrm{CHD}$, whereas radical addition to the $\pi$ system occurred only to a very minor extent. Aliphatic esters (EA) also reacted rapidly with $\mathrm{Oxo}^{+} \mathrm{O}^{\bullet}$ through $\mathrm{HAT}$, preferentially from the ester $\mathrm{O}-\mathrm{CH}_{2}-$ moiety, followed by $\mathrm{CH}_{3}-\mathrm{C}=\mathrm{O}$. The central $-\mathrm{O}-\mathrm{C}_{2} \mathrm{H}_{4}-\mathrm{O}-$ structure in 1,2-DME is particularly susceptible to radicalinduced damage, which is significant since ethylene glycol moieties are constituents of many large-scale industrial polyesters, for example, polyethylene terephthalate (PET). 
The reactivity of $\mathrm{Oxo}^{+} \mathrm{C}^{\bullet}$ was about two orders of magnitude lower than that of $\mathrm{Oxo}^{+} \mathrm{O}^{\bullet}$. An unprecedented alkyl transfer in the reaction of $\mathrm{Oxo}^{+} \mathrm{C}^{\bullet}$ with EA was discovered, which could propagate radical damage in polyesters through a novel homolytic substitution pathway.

In contrast to $\mathrm{Oxo}^{+} \mathrm{O}^{\bullet}, \mathrm{Oxo}^{+} \mathrm{C}^{\bullet}$ more readily undergoes addition to alkenes. Comparison of the rate coefficients for the competing pathways clearly shows that both allylic HAT and radical addition to alkene $\pi$ systems need to be considered as reaction pathways of $C$-centered radicals during polymer degradation. We will in the future employ this strategy to explore the chemistry of secondary radicals, in particular the role of oxygen on the degradation mechanism in step-growth and chain-growth polymers under environmental conditions.

\section{ASSOCIATED CONTENT}

\section{S Supporting Information}

The Supporting Information is available free of charge on the ACS Publications website at DOI: 10.1021/acs.jpca.7b04217.

Kinetic data (Figures S1-S5); mass spectra (Figures S6 and S7); synthetic procedures to alternative radical precursors; general synthetic procedures, ${ }^{1} \mathrm{H}$ and ${ }^{13} \mathrm{NMR}$ spectra; Gaussian 09 archive entries for Figures 6-8 (PDF)

\section{AUTHOR INFORMATION}

\section{Corresponding Author}

*E-mail: uwille@unimelb.edu.au. Phone: +61 (0)3 83442425. ORCID ${ }^{\circ}$

Richard A. J. O’Hair: 0000-0002-8044-0502

Uta Wille: 0000-0003-1756-5449

Notes

The authors declare no competing financial interest.

\section{ACKNOWLEDGMENTS}

Support by the Australian Research Council (DP170100035), The University of Melbourne and the National Computational Infrastructure (NCI) is gratefully acknowledged. We thank Victor Wan and Athanasios Zavras for help with the MS experiments.

\section{REFERENCES}

(1) Gewert, B.; Plassmann, M. M.; MacLeod, M. Pathways for Degradation of Plastics Floating in the Marine Environment. Environ. Sci. Processes Impacts 2015, 17, 1513-1521.

(2) Caruso, M. M.; Davis, D. A.; Shen, Q.; Odom, S. A.; Sottos, N. R.; White, S. R.; Moore, J. S. Mechanically-Induced Chemical Changes in Polymeric Materials. Chem. Rev. 2009, 109, 5755-5798.

(3) Bolland, J. L. Kinetic Studies in the Chemistry of Rubber and Related Materials. I. The Thermal Oxidation of Ethyl Linoleate. Proc. R. Soc. London, Ser. A 1946, 186, 218-236.

(4) Bolland, J. L.; Gee, G. Kinetic Studies in the Chemistry of Rubber and Related Materials. III. Thermochemistry and Mechanisms of Olefin Oxidation. Trans. Faraday Soc. 1946, 42, 244-252.

(5) Bolland, J. L.; ten Have, P. Kinetic Studies in the Chemistry of Rubber and Related Materials. V. The Inhibitory Effect of Phenolic Compounds on the Thermal Oxidation of Ethyl Linoleate. Discuss. Faraday Soc. 1947, 2, 252-260.

(6) Bateman, L. Olefin Oxidation. Q. Rev., Chem. Soc. 1954, 8, 147167.

(7) Gryn'ova, G.; Hodgson, J. L.; Coote, M. L. Revising the Mechanism of Polymer Autooxidation. Org. Biomol. Chem. 2011, 9, 480-490.
(8) Lindsay Smith, J. R.; Nagatomi, E.; Stead, A.; Waddington, D. J.; Beviere, S. D. The Autoxidation of Aliphatic Esters. Part 1. The Reactions of tert-Butoxyl and Cumyloxyl Radicals with Neopentyl Esters. J. Chem. Soc., Perkin Trans. 2 2000, 1193-1198.

(9) Lindsay Smith, J. R.; Nagatomi, E.; Waddington, D. J. The Autoxidation of Aliphatic Esters. Part 2. The Autoxidation of Neopentyl Esters. J. Chem. Soc., Perkin Trans. 2 2000, 2248-2258.

(10) Lindsay Smith, J. R.; Nagatomi, E.; Stead, A.; Waddington, D. J. The Autoxidation of Aliphatic Esters. Part 3. The Reactions of Alkoxyl and Methyl Radicals, from the Thermolysis and Photolysis of Peroxides, with Neopentyl Esters. J. Chem. Soc., Perkin Trans. 2 2001, 1527-1533.

(11) Stirk, K. G.; Kiminkinen, M. L.; Kenttämaa, H. I. Ion-Molecule Reactions of Distonic Radical Cations. Chem. Rev. 1992, 92, 16491665.

(12) Li, C. H.; Khairallah, G. N.; Lam, A. K. Y.; O’Hair, R. A. J.; Kirk, B. B.; Blanksby, S. J.; da Silva, G.; Wille, U. Reaction of Aromatic Peroxyl Radicals with Alkynes: A Mass Spectrometric and Computational Study Using the Distonic Radical Ion Approach. Chem. - Asian J. 2013, 8, 450-464.

(13) Khairallah, G. N.; O’Hair, R. A. J.; Wille, U. Mass Spectrometric and Computational Studies on the Reaction of Aromatic Peroxyl Radicals with Phenylacetylene Using the Distonic Radical Ion Approach. J. Phys. Chem. A 2014, 118, 3295-3306.

(14) Lam, A. K. Y.; Li, C.; Khairallah, G. N.; Kirk, B. B.; Blanksby, S. J.; Trevitt, A. J.; Wille, U.; O’Hair, R. A. J.; da Silva, G. Gas-Phase Reactions of Aryl Radicals with 2-Butyne: Experimental and Theoretical Investigation Employing the N-Methyl-pyridinium-4-yl Radical Cation. Phys. Chem. Chem. Phys. 2012, 14, 2417-2426.

(15) Li, C.; Lam, A. K. Y.; Khairallah, G. N.; White, J. M.; O’Hair, R. A. J.; da Silva, G. Using Distonic Radical Ions to Probe the Chemistry of Key Combustion Intermediates: The Case of the Benzoxyl Radical Anion. J. Am. Soc. Mass Spectrom. 2013, 24, 493-501.

(16) Maccarone, A. T.; Kirk, B. B.; Hansen, C. S.; Griffiths, T. M.; Olsen, S.; Trevitt, A. J.; Blanksby, S. J. Direct Observation of Photodissociation Products from Phenylperoxyl Radicals Isolated in the Gas Phase. J. Am. Chem. Soc. 2013, 135, 9010-9014.

(17) da Silva, G.; Lloyd, C.; Trevitt, A. J.; Blanksby, S. J.; Kirk, B. B. Concerted $\mathrm{HO}_{2}$ Elimination from alpha-Aminoalkylperoxyl Free Radicals: Experimental and Theoretical Evidence from the GasPhase $\mathrm{NH}_{2} \mathrm{CHCO}_{2}{ }^{-}+\mathrm{O}_{2}$ Reaction. J. Phys. Chem. Lett. 2012, 3, 805811.

(18) Kirk, B. B.; Harman, D. G.; Kenttämaa, H. I.; Trevitt, A. J.; Blanksby, S. J. Isolation and Characterization of Charge-Tagged Phenylperoxyl Radicals in the Gas Phase: Direct Evidence for Products and Pathways in Low Temperature Benzene Oxidation. Phys. Chem. Chem. Phys. 2012, 14, 16719-16730.

(19) Williams, P. E.; Jankiewicz, B. J.; Yang, L.; Kenttämaa, H. I. Properties and Reactivity of Gaseous Distonic Radical Ions with Aryl Radical Sites. Chem. Rev. 2013, 113, 6949-6985.

(20) Osburn, S.; Chan, B.; Ryzhov, V.; Radom, L.; O’Hair, R. A. J. Role of Hydrogen Bonding on the Reactivity of Thiyl Radicals: A Mass Spectrometric and Computational Study Using the Distonic Radical Ion Approach. J. Phys. Chem. A 2016, 120, 8184-8189.

(21) Gervasoni, B.; Khairallah, G. N.; O'Hair, R. A. J.; Wille, U. The Role of Peroxyl Radicals in Polyester Degradation - A Mass Spectrometric Product and Kinetic Study Using the Distonic Radical Ion Approach. Phys. Chem. Chem. Phys. 2015, 17, 9212-9221.

(22) Wee, S.; Mortimer, A.; Moran, D.; Wright, A.; Barlow, C. K.; O’Hair, R. A. J.; Radom, L.; Easton, C. J. Gas-Phase Regiocontrolled Generation of Charged Amino Acid and Peptide Radicals. Chem. Commun. 2006, 4233-4235.

(23) Barlow, C. K.; Wright, A.; Easton, C. J.; O'Hair, R. A. J. GasPhase Ion-Molecule Reactions Using Regioselectively Generated Radical Cations to Model Oxidative Damage and Probe Radical Sites in Peptides. Org. Biomol. Chem. 2011, 9, 3733-3745.

(24) O'Hair, R. A. J. The Role of Nucleophile-Electrophile Interactions in the Unimolecular and Bimolecular Gas-Phase Ion 
Chemistry of Peptides and Related Systems. J. Mass Spectrom. 2000, $35,1377-1381$.

(25) Lioe, H.; Barlow, C. K.; O’Hair, R. A. J. How Does Acetylcholine Lose Trimethylamine? A Density Functional Theory Study of Four Competing Mechanisms. J. Am. Soc. Mass Spectrom. 2009, 20, 238-246.

(26) Paulsen, H.; Dammeyer, R. Carboxonium Compounds in Carbohydrate Chemistry, XXIX. Investigation of Charge Distribution in 1,3-Dioxolan-2-ylium Ions. Chem. Ber. 1976, 109, 1837-1849.

(27) Paulsen, H.; Dammeyer, R. Carboxonium Compounds in Carbohydrate Chemistry. 33. Proton and Carbon-13 NMR Studies of Charge Distribution in Substituted 1,3-Dioxan-2-ylium Salts. Org. Magn. Reson. 1979, 12, 616-623.

(28) Perst, H. Oxonium Ions in Organic Chemistry; Verlag Chemie, Academic Press, 1971.

(29) Lum, R. M. Thermal Decomposition of Poly(butylene terephthalate). J. Polym. Sci., Polym. Chem. Ed. 1979, 17, 203-213.

(30) Dawe, R. D.; Molinski, T. F.; Turner, J. V. Dilithium Tetrabromonickelate (II) as a Source of Soft Nucleophilic Bromide: Reaction with Epoxides. Tetrahedron Lett. 1984, 25, 2061-2064.

(31) Jiménez, T.; Campaña, A. G.; Bazdi, B.; Paradas, M.; ArráezRomán, D.; Segura-Carretero, A.; Fernández-Gutiérrez, A.; Oltra, J. E.; Robles, R.; Justicia, J.; et al. Radical Reduction of Epoxides Using a Titanocene(III)/Water System: Synthesis of $\beta$-Deuterated Alcohols and Their Use as Internal Standards in Food Analysis. Eur. J. Org. Chem. 2010, 2010, 4288-4295.

(32) Donald, W. A.; Khairallah, G. N.; O'Hair, R. A. J. The Effective Temperature of Ions Stored in a Linear Quadrupole Ion Trap Mass Spectrometer. J. Am. Soc. Mass Spectrom. 2013, 24, 811-815.

(33) Donald, W. A.; McKenzie, C. J.; O'Hair, R. A. J. C-H Bond Activation of Methanol and Ethanol by a High-Spin $\mathrm{Fe}^{\mathrm{IV}} \mathrm{O}$ Biomimetic Complex. Angew. Chem., Int. Ed. 2011, 50, 8379-8383.

(34) Kuzmic, P. Program DYNAFIT for the Analysis of Enzyme Kinetic Data: Application to HIV Proteinase. Anal. Biochem. 1996, 237, 260-273.

(35) Frisch, M. J.; Trucks, G. W.; Schlegel, H. B.; Scuseria, G. E.; Robb, M. A.; Cheeseman, J. R.; Scalmani, G.; Barone, V.; Mennucci, B.; Petersson, G. A.; et al. Gaussian 09, revision D.01, Gaussian, Inc.: Wallingford, CT, 2013.

(36) Dau, P. D.; Armentrout, P. B.; Michelini, M. C.; Gibson, J. K. Activation of Carbon Dioxide by a Terminal Uranium-Nitrogen Bond in the Gas-Phase: A Demonstration of the Principle of Microscopic Reversibility. Phys. Chem. Chem. Phys. 2016, 18, 7334-7340.

(37) Zabarnick, S.; Heicklen, J. Reactions of Alkoxy Radicals with $\mathrm{O}_{2}$.

I. $\mathrm{C}_{2} \mathrm{H}_{5} \mathrm{O}$ Radicals. Int. J. Chem. Kinet. 1986, 17, 455-476.

(38) Walling, C.; Thaler, W. Positive Halogen Compounds. III. Allylic Chlorination with $t$-Butyl Hypochlorite. The Stereochemistry of Allylic Radicals. J. Am. Chem. Soc. 1961, 83, 3877-3884.

(39) Walling, C. Some Aspects of the Chemistry of Alkoxy Radicals. Pure Appl. Chem. 1967, 15, 69-80.

(40) DePuy, C. H. Understanding Organic Gas-Phase Anion Molecule Reactions. J. Org. Chem. 2002, 67, 2393-2401.

(41) Speranza, M. Kinetics and Mechanisms in Gas-Phase Ion Chemistry by Radiolytic Methods. Mass Spectrom. Rev. 1992, 11, 73117. 


\section{University Library}

\section{- M M N E R VA A gateway to Melbourne's research publications}

Minerva Access is the Institutional Repository of The University of Melbourne

Author/s:

Taggert, BI;O'Hair, RAJ;Wille, U

Title:

Environmental Polymer Degradation: Using the Distonic Radical Ion Approach to Study the Gas-Phase Reactions of Model Polyester Radicals

Date:

2017-07-20

Citation:

Taggert, B. I., O'Hair, R. A. J. \& Wille, U. (2017). Environmental Polymer Degradation: Using the Distonic Radical Ion Approach to Study the Gas-Phase Reactions of Model Polyester Radicals. JOURNAL OF PHYSICAL CHEMISTRY A, 121 (28), pp.5290-5300. https://doi.org/10.1021/acs.jpca.7b04217.

Persistent Link:

http://hdl.handle.net/11343/252776 